\title{
Spatial and Behavioral Correlates of Hippocampal Neuronal Activity
}

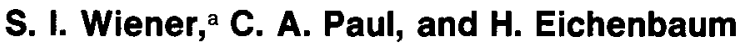 \\ Department of Biological Sciences, Wellesley College, Wellesley, Massachusetts 02181
}

\begin{abstract}
The firing rate of hippocampal neurons in rats was related both to spatial location and to multiple behavioral variables as rats performed 2 kinds of tasks that rely on hippocampal function: a spatial navigation task similar in performance demands to the radial-arm maze task and a simultaneouscue odor-discrimination task. In the place task, most cells had distinct single or multiple place fields, that is, neurons increased firing when the rat was in a particular location or locations. However, in most of these cells, firing rate also varied systematically in relation to behavioral variables, including the speed, direction, and turning angle of the rat as it moved through the place field. In addition, the activity of most cells was time-locked to task-relevant approach movements. In the odor task, most cells fired as the rat sampled discriminative cues or when it executed specific, task-relevant approach movements. Some cells fired selectively in relation to which odors were presented, the configuration of odor cues, the locus of the response, or a combination of these variables. Many cells with spatial correlates in the place task also had striking behavioral correlates when rats performed the odor task in the same environment, and the locus of the increased firing associated with behavior in the odor task was not the same as the place field in the place task. Thus, while the complex stimuli that compose spatial cues are reflected in hippocampal neuronal activity, hippocampal processing is not limited to the representation of spatial location. Rather, the domain of hippocampal representation includes both spatial and nonspatial relations among multiple cues and the actions directed in relation to these cues, across cue modalities, and across behavioral paradigms.
\end{abstract}

Hippocampal complex spike cells demonstrate striking functional correlates both in spatial and in nonspatial bchavioral paradigms. Investigations focused on spatial paradigms, such as mazes or open fields, generally show that hippocampal cells fire primarily in relation to the animal's location in the environment, leading some to view the role of the hippocampus as maintaining a spatial map of the environment (cf. O'Keefe, 1979). Investigations focused on nonspatial sensory discrimination learning paradigms generally report that hippocampal

\footnotetext{
Received Aug. 18, 1988; revised Jan. 20, 1989; accepted Jan. 20, 1989.

We acknowledge the generous support of NIH grant NS18744, BRSG grants to Wellesley College, and NSF grants BNS8721157 and BNS 8810095 . We thank Michael Kuperstein for technical assistance and Neal Cohen, Matthew Shapiro, Nestor Schmajuk, and Cindy Wible for their comments on the manuscript.

Correspondence should be addressed to IIoward Eichenbaum, Science Center, Wellesley College, Wellesley, MA 02181.

aPresent address: Laboratoire de Physiologie Neurosensorielle, 15, rue de l'École de Mćdccinc, 75270 Paris Cedex 06 France.

Copyright (c) 1989 Society for Neuroscience $0270-6474 / 89 / 082737-27 \$ 02.00 / 0$
}

cells fire primarily in relation to critical discriminative cues and behavioral responses, leading other investigators to view the hippocampus as a more general memory processor (cf. Olton, 1988).

There are several possible explanations for differential characterizations of the correlates of hippocampal neuronal activity as "spatial" and as "behavioral." One possible explanation is that hippocampal cells actually fire only in association either with spatial location or with specific learned behaviors and that some investigators have confounded these classes of variables. Consistent with this view, previous experiments have not carefully tested for both types of functional correlate. Indeed, many studies examining spatial behavior strive to equate behavioral events across locations but do not monitor the details of ongoing behavior (Olton et al., 1978; Muller et al., 1987), and many studies of discrimination learning confound the critical behavioral events with the locations where they occur and do not systematically evaluate the influence of spatial factors (Segal et al., 1972; Ranck, 1973; Berger et al., 1983).

A second possible explanation for the observation of both spatial and behavioral correlates of hippocampal neuronal activity is that separate classes of cells are specifically responsible for spatial versus behavioral representations, respectively. Christian and Deadwyler (1986) proposed that complex spike cells encode spatial location and that theta cells demonstrate learning-related sensory-behavioral correlates. However, another preliminary study has shown that the same complex spike cells that had place fields in the radial arm maze also had conditioned responses in a classical conditioning paradigm (Best and Thompson, 1984). Given recent data showing that individual hippocampal complex spike cells might be active in only a few environments (Best, 1988), it remains possible that there are classes of cells that may be primarily active in either spatial tasks or sensory-discrimination learning paradigms, but not both.

A third possible explanation is that the firing rate of complex spike cells depends on the same spatial or behavioral variables (or both) across tasks. Consistent with this view, most investigations reporting either spatial or behavioral correlates claim that the majority of cells has the respective correlate. Unless different populations of cells are being sampled in these studies, it must be that at least some cells have both types of correlate either within or between tasks. If the same cells do have both types of correlate, it is appropriate to ask whether there is a common property across correlates suggesting a processing function fundamental to both.

The present study seeks to describe and compare the spatial and the behavioral correlates of hippocampal neuronal activity in both a spatial memory task and a sensory-discrimination task, each of which has processing demands similar to paradigms that have been shown to be dependent on hippocampal function. Each task was designed to reveal the relevant spatial or behav- 
ioral correlates that have been characterized previously for these sorts of tasks. But, in addition, specific efforts were made to determine the behavioral correlates of unit activity in the spatial lask and spatial correlates of unit activity in the sensory discrimination task. There were 3 specific objectives:

First, the spatial correlates of CA1 complex spike cell activity were determined in rats performing an automated spatial navigation task similar in performance demands to the Olton radial arm maze task (Olton and Samuelson, 1976; hereafter referred to as the place task). Several previous studies have shown that most spontaneously active hippocampal complex spike cells demonstrate place fields in the radial arm maze task (O'Keefe and Speakman, 1987) and that accurate performance in this task depends on hippocampal function (Olton et al., 1979). The firing rate of cells was also examined with respect to 4 quantifiable behavioral variables as measured by movement parameters within the spatial region associated with maximal firing.

Second, the behavioral correlates of cellular activity were determined in rats performing a sensory-discrimination task guided by odor cues (hereafter referred to as the odor task). This task is similar to one previously used by this laboratory to reveal 2 categories of hippocampal complex spike cells distinguished by their behavioral correlates: cue-sampling cells, which fire during the investigation of odor cues and generation of the discriminative response, and goal-approach cells, which fire during approach movements towards task-relevant goals (Eichenbaum et al., 1987). Furthermore, performance on the current task has been shown to be dependent on hippocampal function (Eichenbaum et al., 1988). Multiple analyses were also performed to determine the extent to which firing rate could be explained purely by the spatial location of the animal as it performed the correlated behavior.

Third, since most of the cells were recorded while rats performed both tasks, and since both tasks were performed in the same environment, several questions about the relationship between the 2 sets of functional correlates werc asked. Do the same cells have both spatial correlates in the place task and hehavioral correlates in the odor task? If so, is the place field in the place task at the locus where the critical behavior was performed in the odor task? Or is there a common behavioral correlate that accounts for firing in both tasks? Is the activity of individual cells better accounted for by the spatial correlates in the place task or by behavioral correlates in the odor lask?

\section{Materials and Methods}

\section{Subjects}

Twelve 350-450 gm male Long-Evans rats were kept on a $23.5 \mathrm{hr}$ waterdeprivation schedule and were trained to perform the spatial navigation task prior to surgery for electrode implantation. Half of the rats were also traincd prior to surgery on the odor-discrimination task. After surgery to implant the chronic drivable electrode and a 3-5 d recovery, subjects were retrained and then performed in recording sessions for up to 2 weeks. During this period, the electrodes were surveyed for unit activity at 3-24 hr intervals, and, if none was seen, the electrode was advanced up to $80 \mu \mathrm{m}$ and allowed to settle until the next survey.

\section{Electrodes and surgery}

Subjects that were tested in the odor lask were trained on one discrimination problem preoperatively, then given water ad libitum for at least $48 \mathrm{hr}$ before surgery. Rats were tranquilized with acepromazine, anesthetized with pentobarbital, and given atropine to reduce excess salivation. Body temperature was maintained with a $39^{\circ} \mathrm{C}$ thermal pad. The head was placed in a stereotaxic frame with bregma and lambda level. Using aseptic procedures, the scalp was resected and holes were drilled in the skull. Several devices (see below) were implanted and secured with dental cement and stainless steel skull screws. One screw in the frontal bone also served as the electrical ground. The waterdeprivation schedule and training resumed after a $2-4 \mathrm{~d}$ recovery period.

Each rat was prepared with a combination of 4 devices for monitoring different physiological and behavioral parameters: (1) A microelectrode bundle was constructed with ten $25 \mu \mathrm{m}$ Formvar-insulated nichrome wires threaded through a 26 gauge cannula and clipped to equal lengths (Eichenbaum et al., 1977). This was attached to a vertically driveable connector assembly (Kubie, 1984). The electrode was implanted at coordinates relative to bregma: posterior $3.2 \mathrm{~mm}$, lateral $1.8 \mathrm{~mm}$ on the right side, and $1-1.5 \mathrm{~mm}$ below the pial surface. (2) A twisted pair of Teflon-coated $125 \mu \mathrm{m}$, stainless stecl macroclectrodes with one lead 0.5 mm longer than the other was implanted at the same A-P and M-L coordinates, but contralateral to the fine-wire bundle and with the longer recording site at a subpial depth of $2.2 \mathrm{~mm}$. (3) A stainless steel cannula was implanted in the nasal cavity to permit insertion of a thermocouple for monitoring sniffing as oscillations in nasal air temperature during the inhalation-exhalation cycle (Macrides et al., 1982; Eichenbaum et al., 1987). (4) A light bulb was affixed to the recording head stage for monitoring the animal's position in the chamber.

Recording and data acquisition. Unit and EEG signals were passed initially through a multichannel unity gain JFET preamplifier for impedance matching. All 10 unit channels were recorded simultaneously by a specially designed multichannel differential-amplifier system. The differential reference was selected as a unit channel that had no detectable unit activity. Each channel was amplified 10,000 $\times$ and filtered at 300$1000 \mathrm{~Hz}$, then passed to a separate channel of a specially designed multichannel window discriminator. In cases where 2-3 units on the same channel could be discriminated by visual inspection of the monitors, the amplifier output was passed to multiple window channels for unit separation. Spike-discriminator windows were set to capture all spikes of complex spike cells. Only units with signal-to-noise greater than 2:1 were used. The accuracy of unit isolation was assessed continuously throughout the recording session by comparing the trigger signal of window detection to a display of the action potential waveform. To eliminate recording artifacts, we also monitored a separate unit channel with no detectable unit activity passed to a "wide-open" window (low threshold just above background noise and no high threshold), and all spike events within $100 \mathrm{msec}$ of the noise were ignored in post hoc analyses. When more than 5 noisc events were detected in a trial, the entire trial was eliminated from the analysis. Spike events were passed to a custom designed sample-and-hold interface that was read and reset at $1000 \mathrm{~Hz}$ by interrupt software operating in the background of the behavioral control programs. EEG and sniffing were amplified and filtered at $0.3-40 \mathrm{~Hz}$ and sampled at $100 \mathrm{~Hz}$ by an A/D converter. A custom-built TV camera following system located the light bulb on the rat's head. This location was digitized at $20 \mathrm{~Hz}$ (place task) or $10 \mathrm{~Hz}$ (odor task) and stored as $X$ and $Y$ spatial coordinates.

\section{Behavioral apparatus}

Our apparatus and procedures were adapted from those used earlier to study hippocampal unit firing in rats performing a successive-cue odordiscrimination task (Eichenbaum et al., 1987). The behavioral chamber was a $40 \times 44 \mathrm{~cm}$ floor metallic arena with $50 \mathrm{~cm}$ walls slanted $15^{\circ}$ outward at the top to eliminate recording artifacts caused when the rat bumps its headstage against the walls (Fig. 1). A cul-de-sac along one wall of the chamber contained 2 adjacent conical stimulus sampling ports located $8 \mathrm{~cm}$ above the floor. Infrared photobeam sensors were located at the entrance to the cul-de-sac and at the entry of the sampling ports. Water-reward cups were located at each of the 4 corners of the arena and just outside the cul-de-sac. In both tasks, all stimulus and reward events were controlled via computer. The area was closed within a sound- and light-attenuating box and was illuminated with a $12 \mathrm{~V}$ incandescent lamp.

\section{Place task}

Training. Behavioral testing and data collection were automated for rapid assay of hippocampal unit activity. During the initial shaping, water was made available at irregular intervals at all of the water cups. Behavior was directly observed and rats were considered ready for implantation when they readily approached each of the water cups upon the presentation of rewards. Training after surgery utilized the positional information from the TV tracker interactively to control the onset of a 


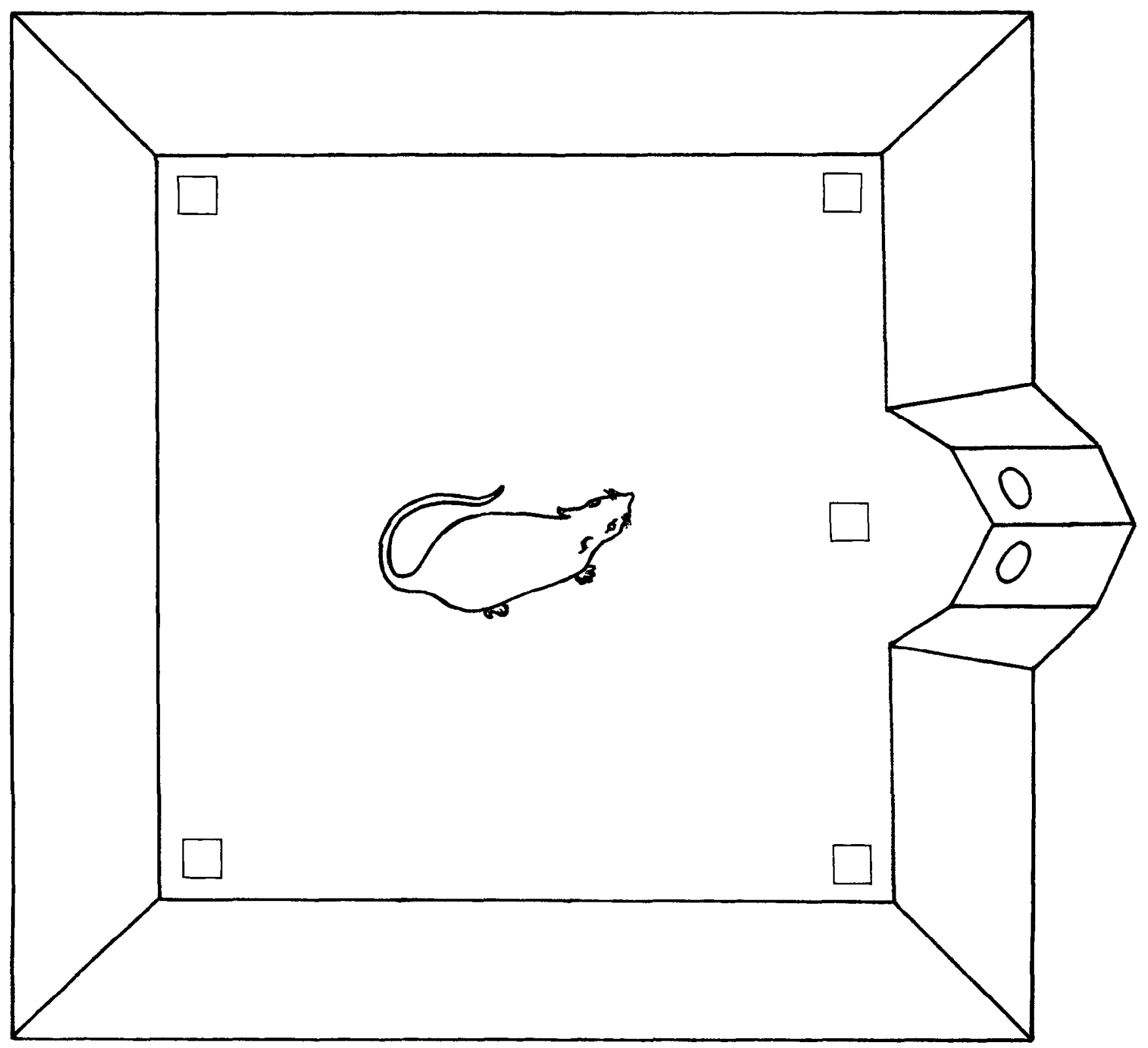

Figure 1. Overhead view of the testing arena with sloped walls. The port area is the alcove in the middle of the right wall. The circles in the walls of the alcove are the 2 sniff ports. The water cups are the small squares located in the corners and in front of the port area.

tonal cue and the delivery of rewards. To initiate a trial, the rat was required to position the lightbulb on its headstage within a $5 \mathrm{~cm}$ radius of the arena center activating a $1 \mathrm{sec}$ duty cycle $900 \mathrm{~Hz}$ "beeping" signal (Fig. $2 \mathrm{~A}$ ). When the rat approached within $2.5 \mathrm{~cm}$ of any of the 4 corners, a $0.05 \mathrm{cc}$ water reward was delivered by a loud solenoid and the beeping signal was silenced (Fig. $2 B$ ). Thereafter, the rat was required to return to the arena center to reinitiate the beep signal and then approach a corner not yet visited that trial. Repeat visits to a corner within a trial and visits not preceded by initiating the beep signal were not rewarded. After visiting all 4 corners, trial initiation was not allowed for a $30 \mathrm{sec}$ intertrial interval.

Data analyses. The analyses of spatial firing correlates focused on the determination of place fields, that is locations associated with increased firing regardless of ongoing behavior. Subsequent analyses considered the importance of qualitative and temporal aspects of movement within the place field.

Characterization of place fields. There is no generally accepted method for defining the spatial boundaries of firing increases, and, indeed, the boundaries of place fields are seldom sharp (see below). Yet to determine the qualities of firing within the place field, specific boundaries must be assigned. In the present study, we characterized and compared place fields determined by a method based on the reliability of increased firing during repeated visits to locations centered upon the same areas.

The area of the arena was divided into an array of $18 \times 16$ (the larger dimension included the cul-de-sac) 2.5-cm-sq "pixels." The statistical likelihood of increased firing on repeated "visits" to individual pixels was determined. The firing rate for each visit to a pixel was calculated as the number of spikes accumulated while the rat was within a $3 \times 3$ pixel area centered on the target pixel. The beginning of a visit was identified as 3 sequential observations of the rat inside the area; similarly, the end of the visit was identified after 3 sequential observations of the rat outside the area. The mean firing rate for each pixel was calculated as the average for all visits to that pixel during the recording session, and a grand mean firing rate and its SE were calculated from the rates for all visits to all pixels. To determine the boundaries of the place field, we compared the mean firing rate of each pixel to the grand mean. Since the total number of visits was several hundred even for the shortest recording session, we considered statistically significant an increase in firing rate at least 2.33 SE above the grand mean (1-tailed $p<0.01$ ). A place field was defined as a set of at least 3 adjacent pixels 


\section{A. SPATIAL NAVIGATION PARADIGM}

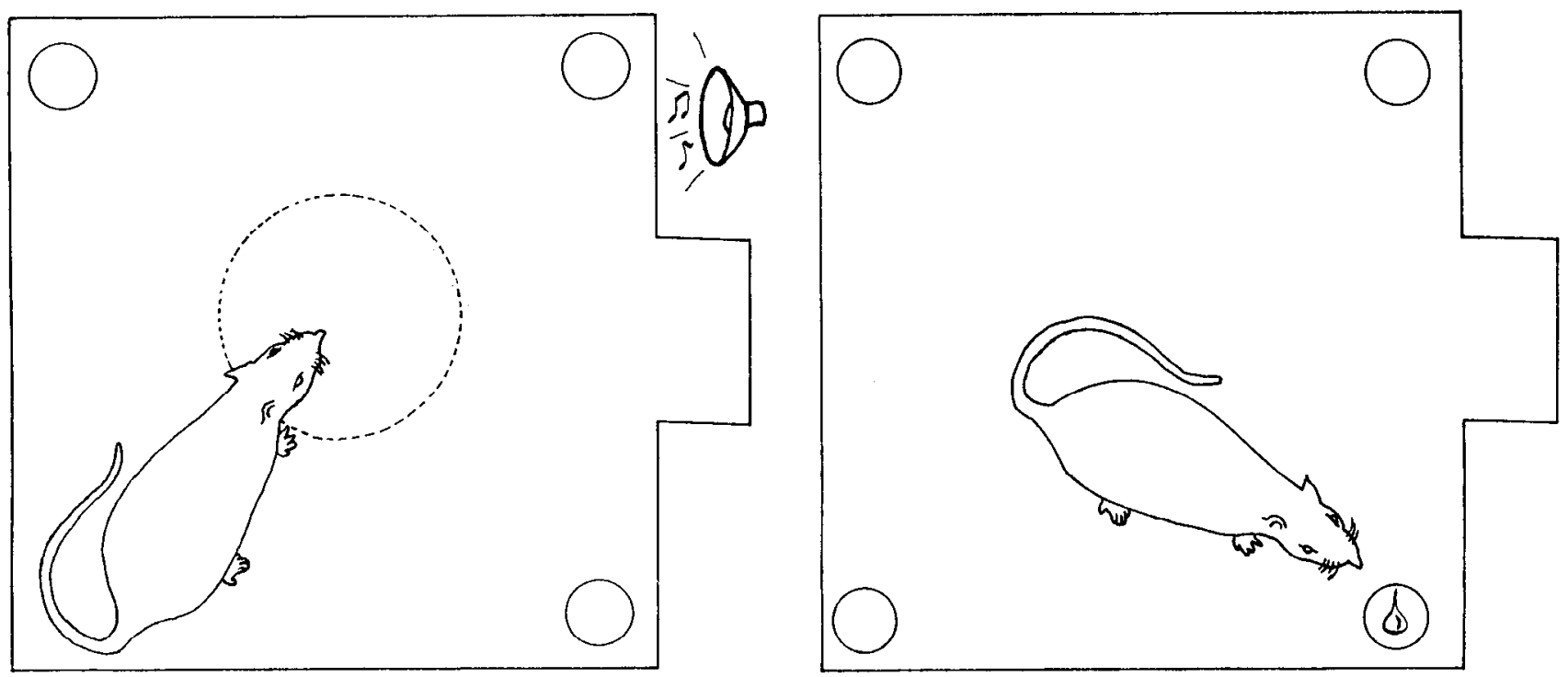

\section{B. EXAMPLES OF MOVEMENT TRACINGS FOR SAMPLE TRIALS}
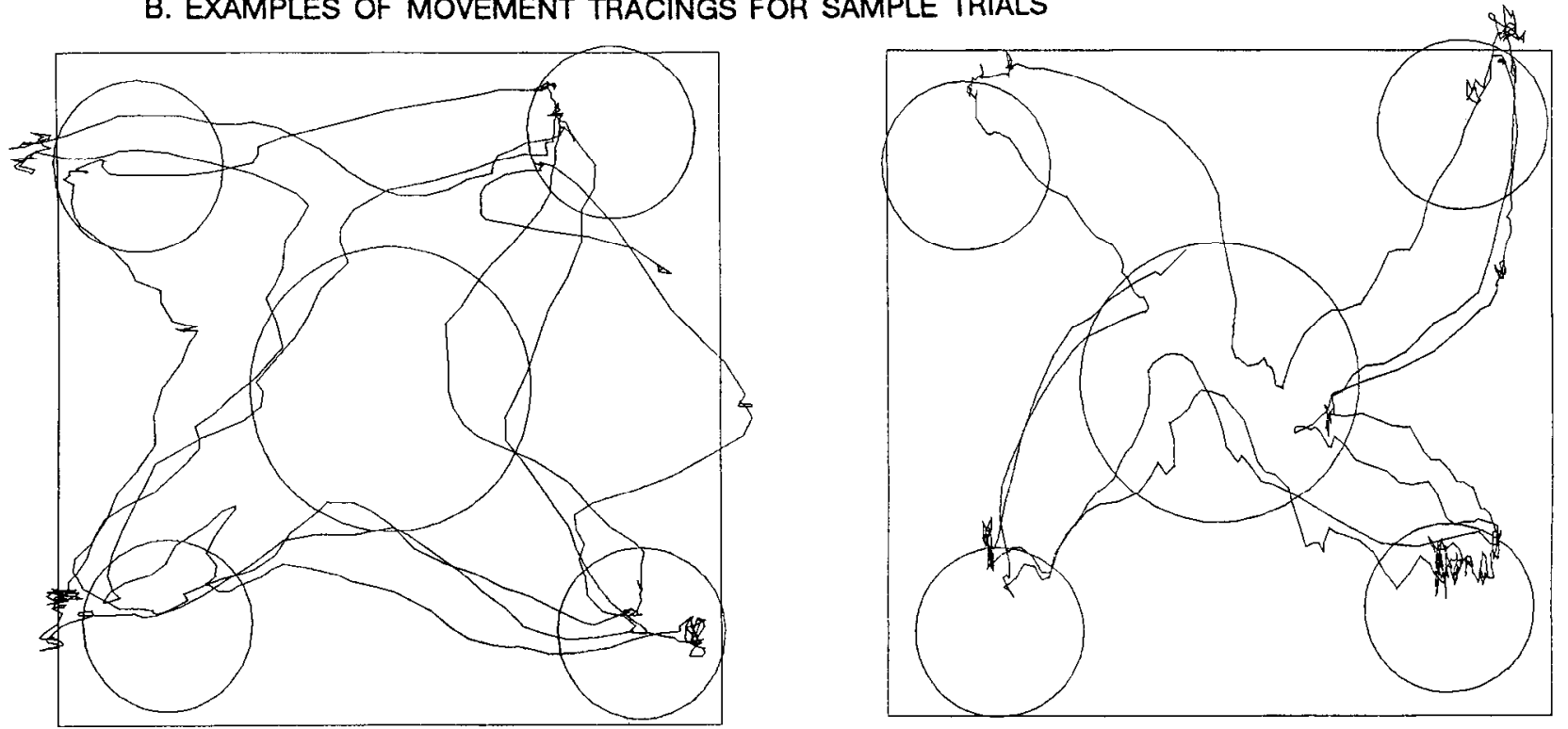

Figure 2. The spatial navigation task. A, The behavioral paradigm. Left panel, a rat enters the center of the arena, indicated here by the dashed line (but not visible in the arena), activating the beeping tone that signals the availability of rewards at cups not yet visited. Right panel, the rat approaches a water cup, activating the delivery of reward. The location of the cul-de-sac is indicated as a rectangular area at the right of each outline. $B$, Sample trial data. Tracings indicate the path taken by the rat during 2 trials. Circles indicate the radius around the water cups and center used by the computer to control task events. Left, Example of a trial where the rat approached cups without properly initiating the approach by returning to the center of the arena. Right, Example of a trial where the rat correctly initiated each run to a cup but made repeated errors of revisiting 3 of the cups.

meeting the firing rate criterion. The degree of spatial "tuning" for each cell was defined as the ratio of its average firing rate in the place field to that outside the place field.

Behavioral correlates of firing within the place field. In order to determine whether location was the only determinant of firing within the place field, we examined the relationship between firing rate in the field (hereafter referred to as "infield" firing) and each of 3 movement (second-order spatial) variables, speed, direction, and turning angle. In addition, to examine whether unit activity was related temporally to specific approach movements, spike activity was time-locked to reward onset at each of the water cups.

The instantaneous speed of movement associated with each observation within the field was estimated by the total distance traveled from 100 msec before to 100 msec after that observation. The firing rate at each location was estimated by counting the number of spikes over the
$50 \mathrm{msec}$ observation period associated with the target location. We examined the relationship of movement speed to firing rate by averaging firing rate samples within $4 \mathrm{~cm} / \mathrm{sec}$ speed bins, then plotting the mean firing rates and their SE in a histogram.

The instantaneous direction of movement associated with each location within the field was estimated using the vector between sequential location observations over the same $200 \mathrm{msec}$ period used for the speed determinations. Direction of movement was determined only for locations when the rat was traveling at a minimum speed over $8 \mathrm{~cm} / \mathrm{sec}$. We examined the relationship of firing rate to direction by averaging firing rate samples within $45^{\circ}$ directional bins, then plotting the means and SE in a polar plot. Note that since this measure of direction is based on a time-series of single data points, the measure quantifies the direction of the rat's movement and not necessarily its direction of "vicw."

The instantaneous angle of turning at each infield location associated 
A. TONE ON

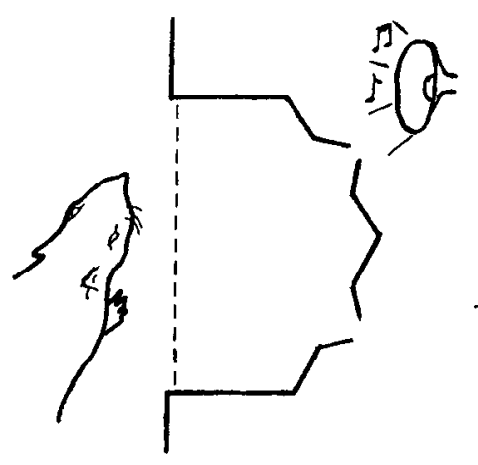

B. INITIATE

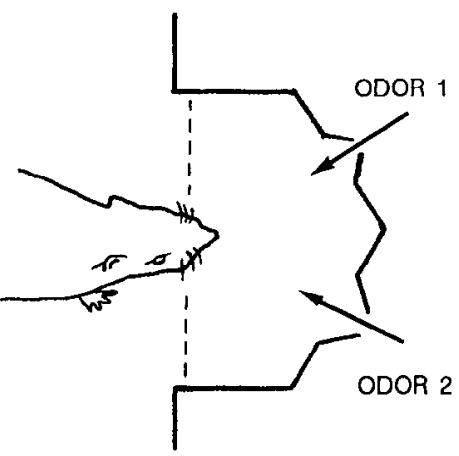

C. NOSE POKE

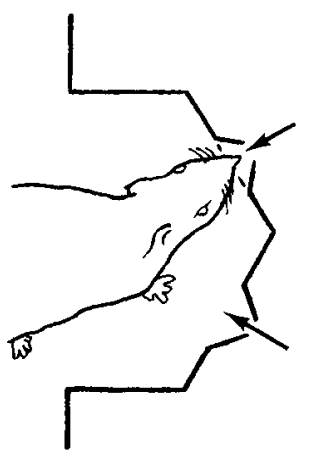

D. WATER

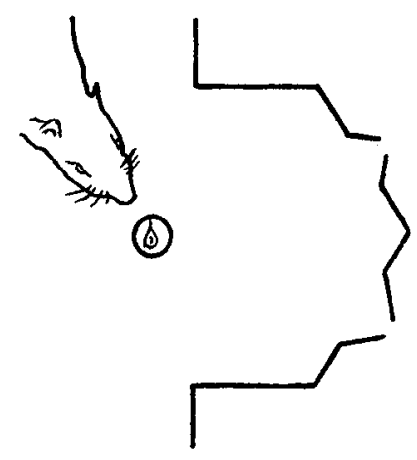

Figure 3. The simultaneous-cue odor-discrimination task. $A$, The availability of a new trial is signaled by a tone. $B$, As the rat enters the port area breaking a photobeam, odors are released from the 2 ports. $C$, The rat selects one odor by executing a nose-poke into the funnel-shaped opening of the port, terminating odor presentation. $D$. If the correct port was selected, a water reward was automatically delivered to the cup.

with over $8 \mathrm{~cm} / \mathrm{sec}$ speed was estimated as the arc subtended by vectors drawn between that location point and points $100 \mathrm{msec}$ before and after that point. We examined the relationship between firing rates and turning angle using the same method as for evaluation of directional firing. Also, as with the direction measure, turning angle here represents the direction of angular movement, not necessarily the change in viewing angle. Firing rate samples were averaged within $45^{\circ}$ angular bins, and the means and SEs were plotted in a polar plot.

The statistical reliability of tuning to each movement variable was evaluated with $a \chi^{2}$ analysis by comparing firing rate observations across all speed or directional bins composed of at least 5 observations. When the $\chi^{2}$ was significant, a measure of "tuning" for each variable was defined as the ratio of the maximum versus minimum nonzero firing rate across bins.

We also characterized unit activity in relation to the movement associated with a successful approach to the reward cups. Firing was averaged for $2 \mathrm{sec}$ before and after the onset of water reward in 100 msec bins and plotted in separate histograms for each of the 4 reward cup locations. Time-locked firing was considered significant if the maximum firing rate in a histogram bin within $1 \mathrm{sec}$ of the time lock was at least 2.5 times the overall average firing rate of the cell.

\section{Odor task}

Olfactometer. Odor stimuli were diluted and controlled by a flow-dilution olfactometer composed of glass, Teflon, odorless urethane hose (Clippard 3814), and stainless steel solenoid valves under computer control. Pressurized air was dehydrated with calcium chloride, deodorized with activated charcoal, and then rehydrated by bubbling through de-ionized water. Control of airflow was accomplished via solenoid valves located before and after each odor reservoir. In addition, a pair of "final" valves, located just outside each port, determined whether the airstream was sent into the sniff port or to a vacuum exhaust. During the intertrial interval (ITI), clean airstreams passed to each of the final valves at $1000 \mathrm{ml} / \mathrm{min}$ and were exhausted. Two seconds before the trial was permitted, valves in the appropriate odor channels were activated, adding $100 \mathrm{ml} / \mathrm{min}$ odor streams to each clean air stream. When the rat crossed the photobeam, the final valves were activated allowing the diluted odors to flow into the ports.

The odor pairs were eugenol versus geraniol (referred to below as odor pair 1-2) and orange versus almond food flavorings (Durkee; referred to below as odor pair 3-4). Each odor was initially diluted to 10 $\mathrm{gm} \%$ in propylene glycol, and the vapor from these solutions was further flow-diluted to $10 \%$ of the delivery airstream.

Training. Initial shaping without odor stimuli proceeded in gradual stages under computer control. First, the rat was shaped to poke its nose into one of the ports to obtain $0.05 \mathrm{ml}$ of water delivered into the reward cup located inside the cul-de-sac just between the 2 sniff ports. During this stage of shaping, nose-pokes made to the same port on more than 2 sequential trials were not rewarded in order to prevent development of a spatial preference. During the second stage of shaping, the reward cup was moved just outside the port area, and the rat was required to wait outside of the port area until a $400 \mathrm{IIz}$ tone sounded (Fig. $3 A$ ). In the final shaping stage, the ITI was gradually increased to $8 \mathrm{sec}$.
Finally, during odor-discrimination training, the odors were delivered through the ports as the rat entered the cul-de-sac (Fig. $3 B$ ). A reward was given for a nose-poke at the port releasing the odor designated as the positive stimulus $\left(\mathrm{S}^{+} ; \mathrm{Fig} .3, C, D\right)$. No reward was given for a nosepoke at the port emitting the designated negative stimulus $\left(\mathrm{S}^{-}\right)$. Either response terminated odor presentation and was followed by the ITI Rats were trained to a performance criterion of 18 correct out of 20 trials for 3-5 successive days prior to surgery. In postoperative recording sessions, the odor pair of the second discrimination problem was added to the stimulus sequence. Every 48 trial block included an equal number of each of the odor pairs and an equal number of presentations of each odor at each port, presented according to a pseudo-random schedule. Each stimulus configuration was equally likely to follow each of the others and itself. One or two recording sessions of 200-240 trials were given each day for most rats. Rats who were also to be tested on the place task were given only $96-120$ odor discrimination trials.

Data analysis. Initial analyses were focused on determining the behavioral correlates of unit activity. These analyses exploited the repetitive nature of the sequence of behavioral and physiological events occurring on each trial. Thus, in raster display analyses, firing was timelocked and averaged around the onset of each event. The importance of spatial location was subsequently evaluated by plotting the location of the animal's head and unit activity during selective trial periods associated with the behavioral correlate.

Raster display analyses. We directly compared how well independently defined events could account for variations in unit activity over the same general time period. The trial events used for synchronization were (1) the onset of the tone signaling the beginning of a trial; (2) the entry into the cul-de-sac; (3) the nose-poke response at 1 of the 2 odor ports; and (4) the approach toward the reward cup (see Fig. 3). Raster displays and summary perievent histograms were constructed to display the averaged, event-synchronized unit activity from $2 \mathrm{sec}$ before until $2 \mathrm{sec}$ after each trial event. The combination of the histograms from the 4 events spanned the entire sequence of the trials.

Since each unit was recorded for many trials, it was possible to statistically test whether unit activity was reliably increased during specific trial periods. Based on our previous analyses of hippocampal complex spike cells in rats performing a successive-cue version of the same odor discriminations (Eichenbaum et al., 1987), we expected that cells with behavioral correlates in the odor task would fall into the 2 functional categories described in the introduction: cue-sampling cells that fire during the period between trial initiation and response onset, and goalapproach cells of 2 subtypes, port-approach cells that fire just before or during the trial initiation, and cup-approach cells that fire after the nosepoke response as the rat approaches the water cup. Based on these expectations, we developed analyses defining each cell type by 2 strict and exclusive criteria that tested first for reliably increased firing during a broadly defined trial period, and then second, for maximal firing during within a restricted segment of that period. The broad periods tested statistically were for the cue-sampling correlate, $300 \mathrm{msec}$ after the trial initiation until the nose-poke; for the port-approach correlate, $500 \mathrm{msec}$ before and after the trial initiation; and for the cup-approach correlate, from 300 to $1000 \mathrm{msec}$ after nose-poke. The periods when the cell had to reach maximal firing rate were as follows: for cue-sampling cells, 

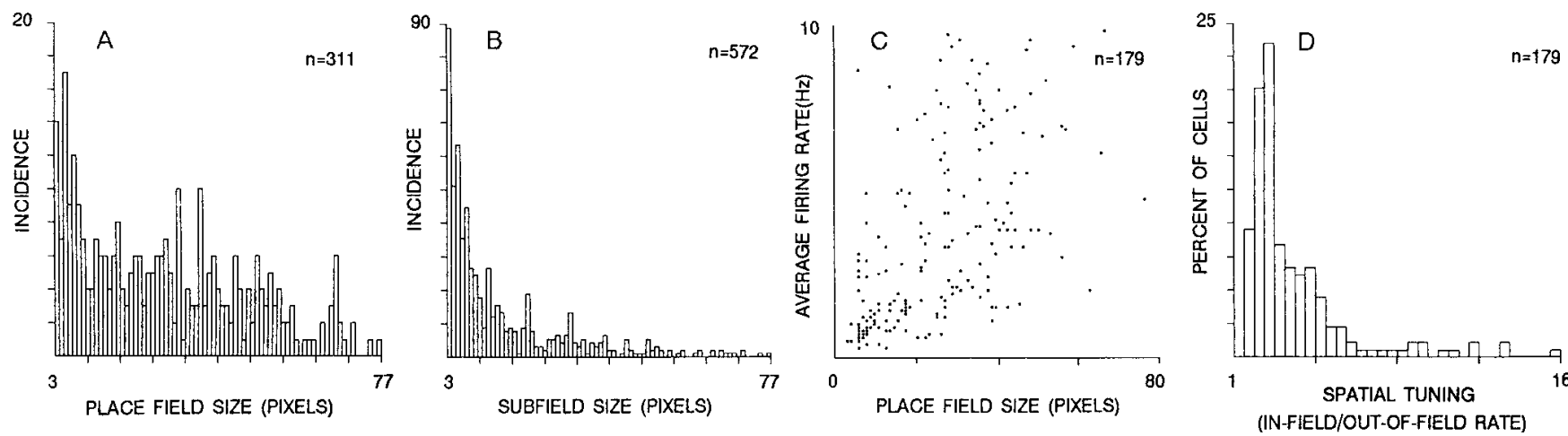

Figure 4. Normative data on place fields. Distributions of the sizes of the total place field $(A)$ and of subfields taken separately $(B)$ represent the data on all cells with a place field composed of at least 3 pixels. Distributions of total place field size according to average firing rate $(C)$ and spatial tuning for the total place field $(D)$ represent only those cells used in analyses of second-order spatial (movement) variables.

between $400 \mathrm{msec}$ after the trial initiation to $100 \mathrm{mscc}$ after the noscpoke; for port-approach cells, between $300 \mathrm{msec}$ before and $300 \mathrm{msec}$ after trial initiation; and for cup-approach cells, between 300 and 1000 msec after the nose-poke. Cells that met both criteria in more than one category were assigned to a special category if the smaller firing peak was within $30 \%$ of the larger one; otherwise, only the period associated with the larger peak was considered.

To perform the statistical analyses, the background firing rate of a cell was measured during the $2 \mathrm{sec}$ period preceding the tone at the beginning of each trial. The firing rate during the key trial periods defined by the events described above were determined and paired $t$ tests (2tailed) were carried out to determine if the firing during these periods changed relative to background firing. For all units with significant ( $p$ $<0.05$ ) increases in firing, a further series of post hoc analyses was applied to test if firing rates increased preferentially during trials with specific stimulus configurations. Specifically, the firing rates during the period of increased firing were compared among the 4 types of trials (2 odor pairs in left and right configurations) using an analysis of variance (ANOVA).

Finally, spike activity was time-locked to relevant variations of each task event to uncover in greater detail other behavorial and physiological parameters that minimized the dispersion of the unit firing envelope, that is, best synchronized unit firing. This was done by time-locking unit activity to specific movements or to the sniff cycle or theta rhythm. The relationship of unit activity to the sniff cycle or theta rhythm during periods of increased firing was also analyzed by determining the phase of each spike relative to inhalation peaks or to negative theta peaks in the filtered $(5-10 \mathrm{~Hz})$ hippocampal EEG, and collecting the phases in $22.5^{\circ}$ bins. The reliability of differences in the firing rate across phase angles was determined by a $\chi^{2}$ analysis, and the optimal phase angle was estimated by determining the best-fitting sine wave (Kuperstein et al., 1986).

Spatial analyses. The movements of the rat during the trial were reconstructed within an outline of the behavioral chamber by plotting a series of points to represent the rat's location at $100 \mathrm{msec}$ intervals for $2 \mathrm{sec}$ before and after synchronization events associated with increased firing. Squares of area proportional to the number of spikes occurring during each interval were superimposed on each location point. These maps of unit activity along the movement path were examined to determine if increases in unit activity occurred at a specific location and to compare locations associated with increased firing across different types of trials defined by the odor-pair used, the spatial configuration of odor presentation, and the response locus.

\section{Results}

\section{Single-unit characteristics}

Before the data-collection sessions, nearly all cells appeared to fire spontaneously at a low rate (approximately $1 \mathrm{~Hz}$ ). None burst reliably with the theta rhythm at the onset of movement, as defines theta cells (Fox and Ranck, 1975). Complex spikes were observed in many, but not all cells. Signal-to-noise ratios ranged from $2: 1$ to $15: 1$. The width of the negative wave of filtered action potentials was uniform, averaging $0.25-0.4 \mathrm{msec}$ at baseline. The locations of unit recordings were identified in post hoc histological analyses as near or within the pyramidal layer of the CA1 field. The average rates reported below were somewhat higher than those reported elsewhere for hippocampal complex spike cells, but our analyses are based on selected periods of maximal behavioral activity, our units were not preselected for having place fields or for low spontaneous firing rate, and we counted all spikes within a complex spike.

\section{Place task}

\section{Behavioral performance}

A total of 93 recording sessions yielded 18-100 trials each. Animals varied in the vigor and accuracy with which they obtained the rewards, achieving an average of 2.6 rewards within the maximum $35 \mathrm{sec}$ trial. In addition, some rats frequently ran from cup to cup without reinitiating the trial by returning to the arena center. These hehavioral patterns led to an approximately uniform sampling of locations within the arena (see below).

\section{Place fields}

Of 415 cells held for long enough to allow a preliminary analysis, $311(75 \%)$ had a place field. The mean size of place fields was 18 of a possible 264 pixels, but total field size varied from the minimum of 3 pixels or $1 \%$ of the arena to 77 pixels or $29 \%$ of the arena (see Fig. $4 A$ ). In 169 (54\%) of these cells, the place field was composed of multiple separated areas of increased firing that we will refer to as subfields: $101(32 \%)$ had 2 subfields, $47(15 \%)$ had 3, $18(6 \%)$ had 4 , and $3(1 \%)$ had 5. Although the mean size of a subfield was 15 pixels, the distribution of subfield sizes was skewed. Most subfields were smaller than the mean: $330(57 \%)$ of the 572 subfields were 10 or fewer pixels (see Fig. $4 B$ ). The spatial tuning ratio (infield rate: out-of-field rate) varied from $1.1: 1$ to $34: 1$ (mean $=5.0: 1$ ), with $65 \%$ under $4: 1$ and $88 \%$ under $9: 1$.

Our examination of neuronal activity properties within place fields required selecting cells that had sufficient data for sampling all values of the movement variables. Thus, we restricted further study to the 179 cells that had place fields of at least 5 pixels, average firing rates under $10 / \mathrm{sec}$, and recording sessions of at least 24 trials. Within this group of cells, place field size was 


\section{A. INCIDENCE OF PIXELS USED (MAX-415)}

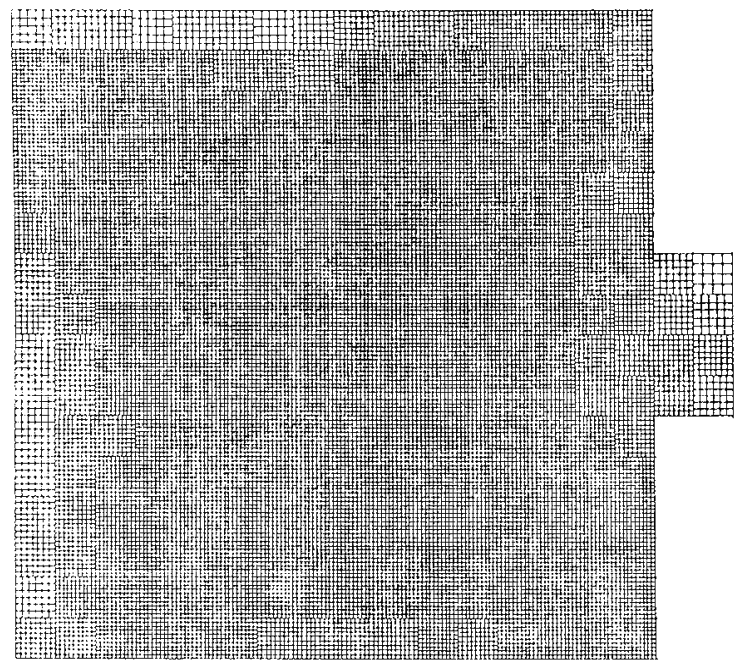

\section{B. INCIDENCE OF PIXELS IN PLACE FIELDS (MAX=71)}

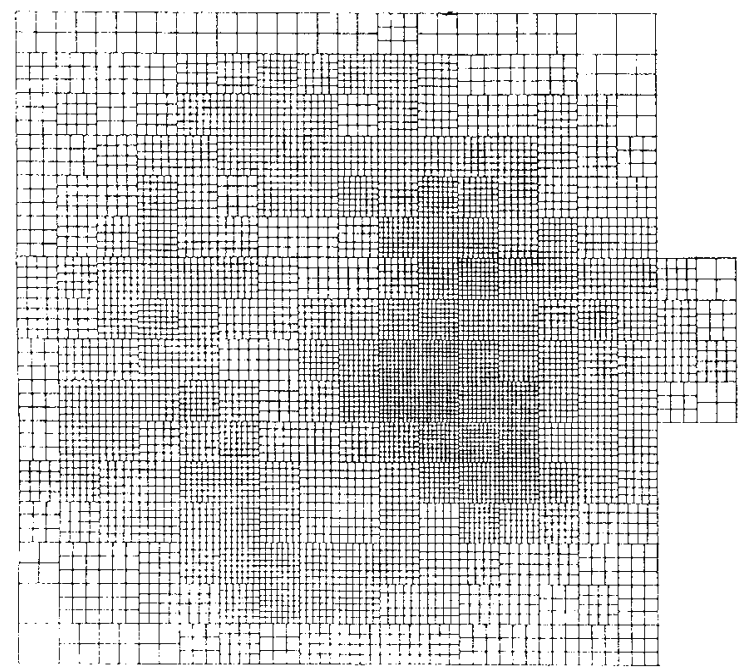

C. MONTE CARLO DISTRIBUTION OF PLACE FIELDS

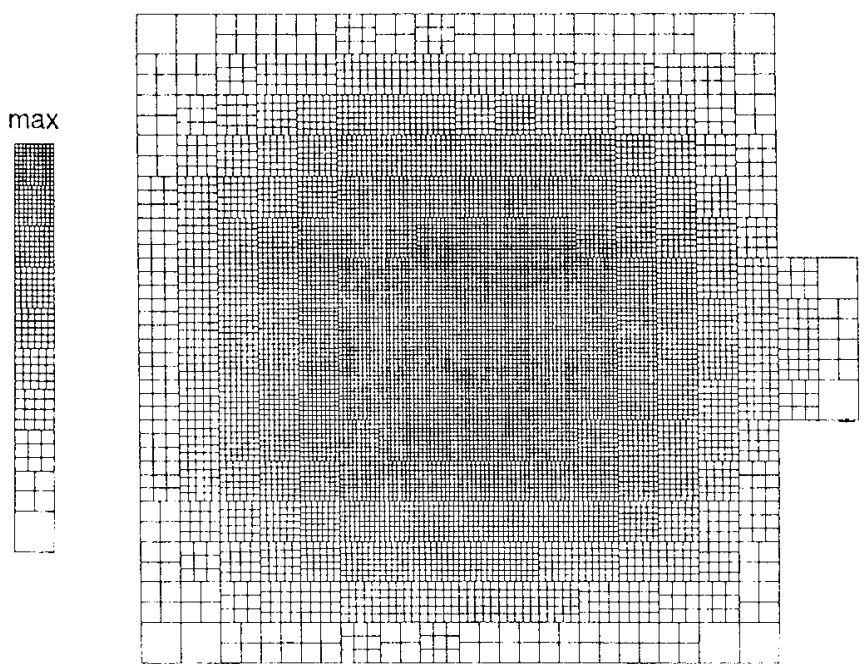

D. DISTRIBUTION OF PIXELS OVER- OR UNDERREPRESENTED BY PLACE FIELDS.

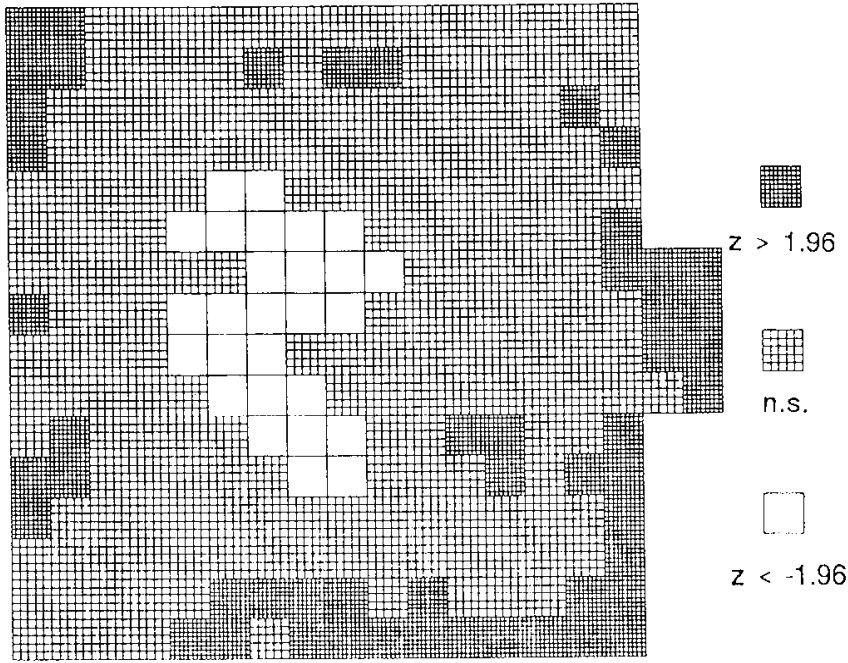

Figure 5. Distribution of the rats' movements and place fields for all cells combined. $A$, Number of recording sessions when each pixel was visited at least the minimum number of times required for use in the determination of a place field. $B$. Number of times each pixel was included in a place field. $C$, Normalized incidence of each pixel included in a random (Monte Carlo) distribution of the same place fields. $D$, Pixels with significantly greater (dense shading) or lesser (white) incidence observed in place fields (as in $B$ ) compared with what would be expected from the Monte Carlo analyses (as in $C$ ).

weakly but significantly correlated with firing rate $\left(r^{2}=0.17, F\right.$ $=83, p<0.001$ ); cells with the highest average firing rates had the largest fields (Fig. 4C). The mean spatial tuning ratio within this group of cells was 5.6:1 and varied from 2:1 to 16:1 (Fig. $4 D)$.

With the exception of the boundaries of the arena, animals visited all parts of the environment equally often (Fig. $5 \mathrm{~A}$ ). An analysis of the incidence of pixels included in place fields indicated they were distributed throughout the arena (Fig. $5 B$ ). To determine if the representation of pixels was different than chance, we compared the incidence of each pixel's inclusion in observed place fields with that of a Monte Carlo distribution constructed from 1000 replications of each place field positioned and oriented randomly within the environment (Fig. 5C). Figure $5 D$ shows the $z$-score for the incidence of representation of each pixel based on an exact probability calculation (Siegel, 1958).
The distribution of $z$-scores indicates a less-than-chance (2tailed $p<0.05$ ) incidence of pixels near the center of the arena and somewhat greater than chance incidence at places along the periphery, an observation commonly noted in previous studies of place fields.

\section{Movement correlates}

Of the 179 cells considered, $124(69 \%)$ had significant speed tuning, $138(77 \%)$ had significant directional tuning, and 111 (62\%) had significant angular tuning. Most cells tuned for one of these variables were also tuned for at least one of the others. In nonexclusive counts, 106 (59\%) cells were tuned for both speed and direction, $93(52 \%)$ for both speed and turning angle, $101(56 \%)$ for direction and turning angle, and $87(49 \%)$ for all 3 variables.

The variation observed among cells for tuning to each of the 
A
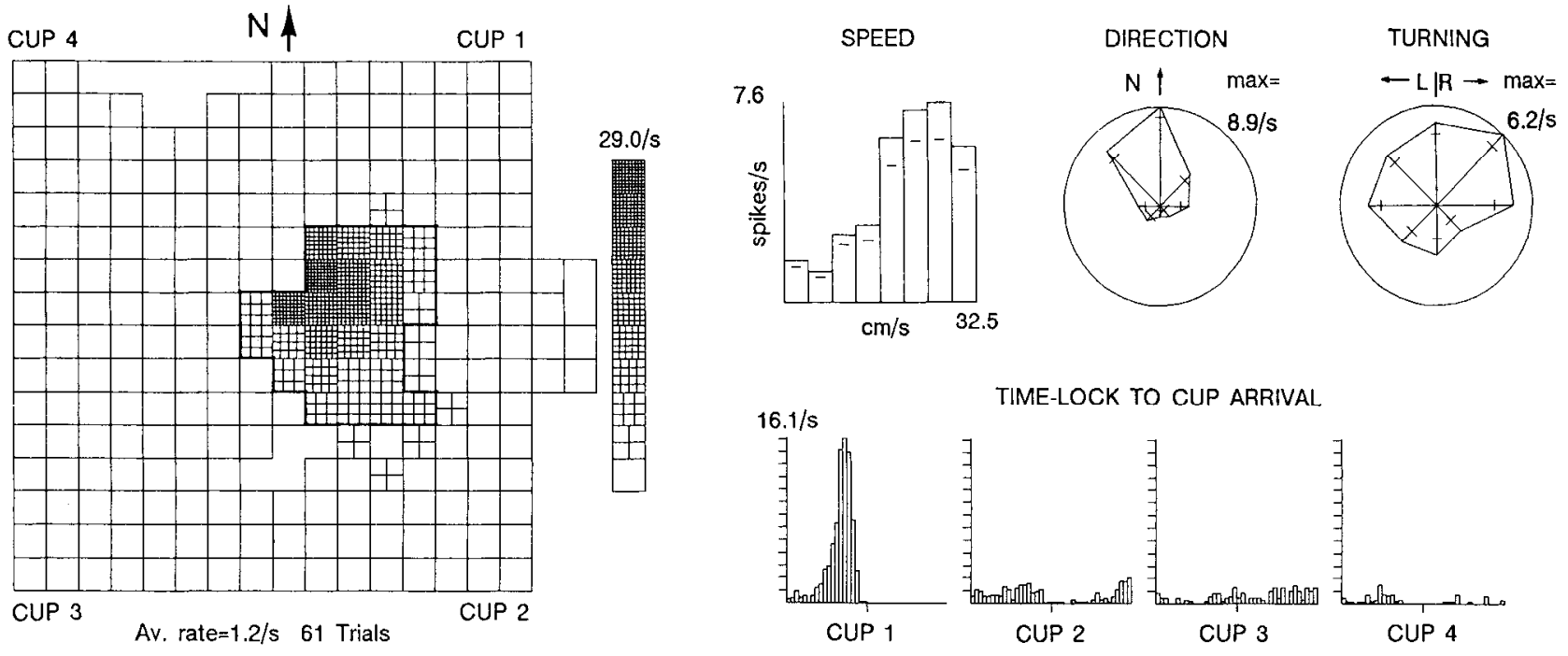

B
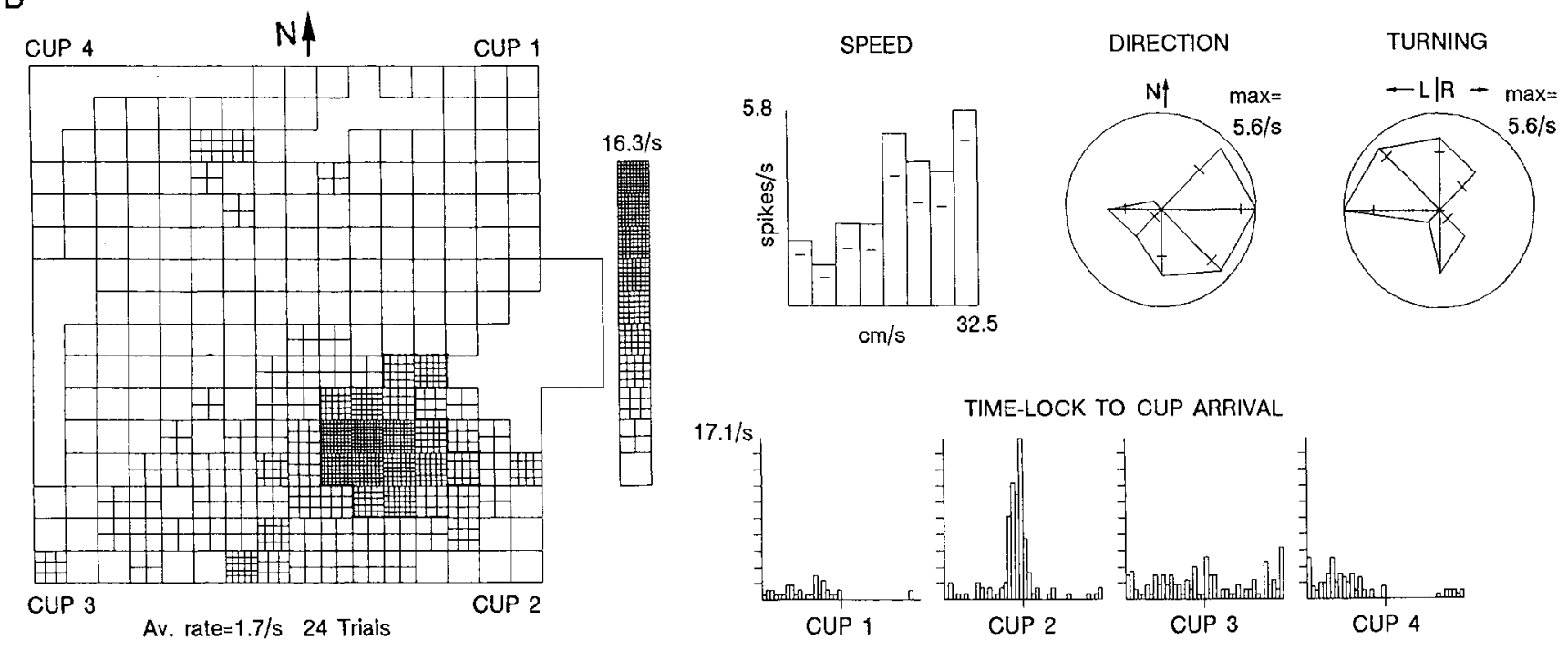

Figure 6. Examples of analyses of unit activity in relation to spatial variables and goal-directed movements in 4 cells. Each analysis is composed of (1) at the left, a firing rate map, indicating the firing rate at each pixel and outlining the boundaries of the place field (or subfields); the firing rate scale is at the right of each map, (2) bottom right, 4 histograms showing unit activity time-locked for \pm 2 sec around the arrival at each reward cup during the same session; a tic mark on the abscissa indicates arrival time; tic marks on ordinate indicate multiples of the average firing rate, and at the top right (from left to right): (3) histogram(s) showing average firing rate at different speeds of movement within each subfield (bars indicate SE), (4) polar plot(s) showing average firing rate for different directions of movement within each subfield (cross bars indicate SE; no line is plotted for directions with less than 5 data samples), and (5) polar plot(s) showing average firing rate at different turning directions during movement within each subfield. Conventions are the same as those for directional tuning plots. Twelve o'clock is straight ahead. $A$, This cell had a single subfield (spatial field tuning ratio $=21.2$ ). Firing was significantly increased during approach to cup $1(13: 1)$, and the cell was significantly tuned to speed (tuning ratio $=6.5$, minimum $n$ [smallest number of observations in a bin] $=132, \chi^{2}=258, d f=7, p<0.001$ ), direction (tuning ratio $=21$, minimum $n=66, \chi^{2}=144, d f=7, p<0.001$ ) and turning angle (tuning ratio $=2.7$, minimum $n=64, \chi^{2}=16.0, d f=7, p<0.05$ ). $B$. This cell had a place field near cup 2 and fired maximally $(10: 1)$ on an eastward approach to that cup at moderate and high speeds. Spatial tuning ratio $=8.2$; speed tuning ratio $=4.8$ (minimum $n=75, \chi^{2}=50.1, d f=7, p<0.001$ ); direction tuning ratio $=19$ (minimum $n=28, \chi^{2}$ $=21.5, d f=7, p<0.01$ ), turn tuning ratio n.s. $C$. This cell had a place field near the center of the arena, fired on approaches to all cups, maximally on the approach to cup 1 (cup $1: 9.3: 1$, cup $2: 4.6: 1$, cup $3: 3.7: 1$, cup $4: 3.4: 1$ ), and was tuned to a moderate speed, bidirectional movement, and

movement variables was great. Furthermore, most cells were uniquely tuned to each parameter when the rat was in each of the subfields. The examples of Figure 6 illustrate a few of the variations in the pattern of correlates observed; normative data and some of the consistencies in these patterns are described below (Fig. 7).

Speed. Of all 293 subfields evaluated, 138 (47\%) of them had significant speed tuning. Cells varied in the speed of movement at which maximal firing was observed. A plurality of cells (37\%) fired at greater rates the faster the animal moved (Fig. $7 \mathrm{~A}$, left), and a few (7\%) fired maximally when the animal was moving at less than $4 \mathrm{~cm} / \mathrm{sec}$, but the majority of cells (56\%) was optimally turned to a speed intermediate between the lowest and highest speeds of movement observed. The speed associated 

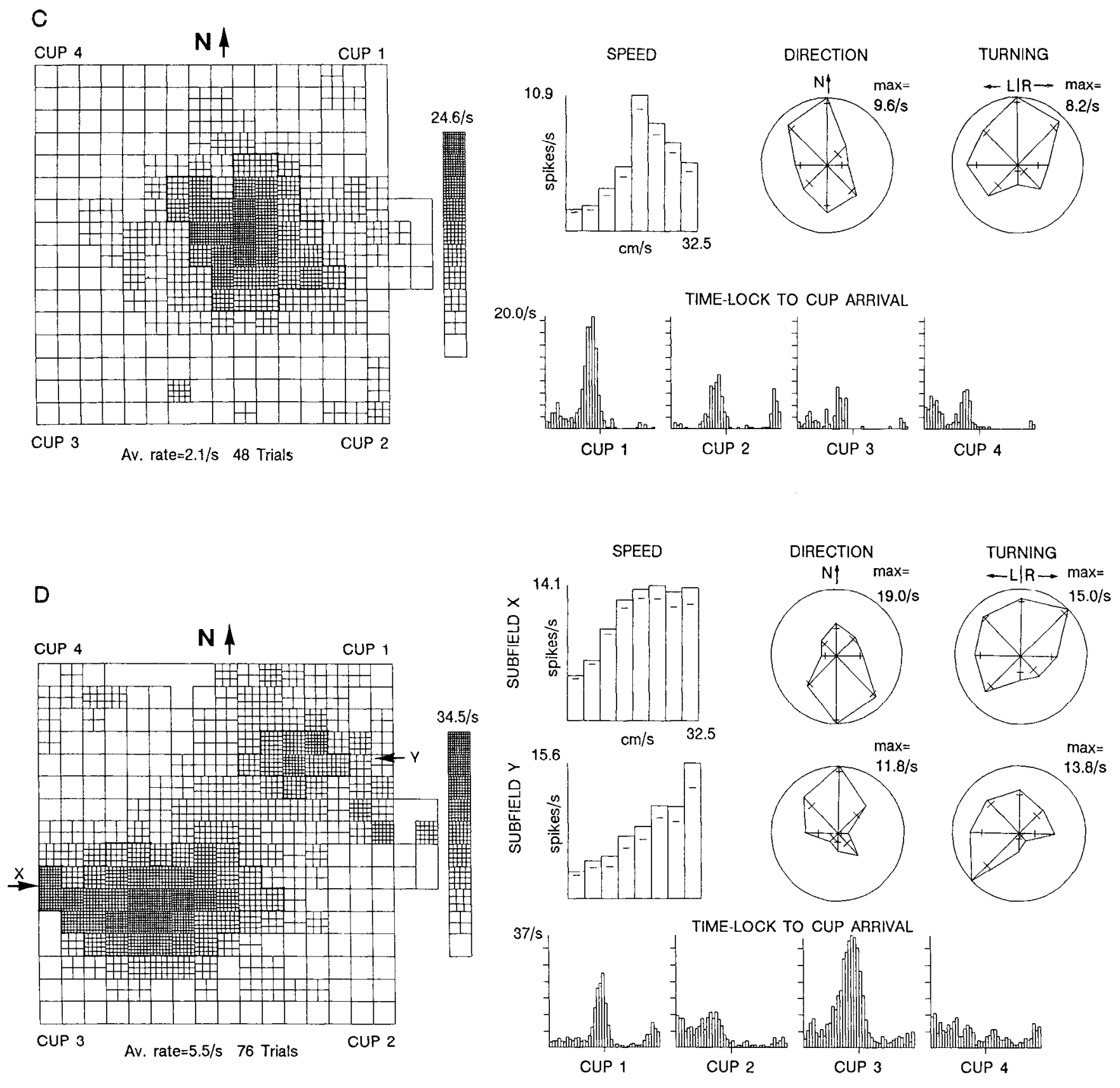

a slight left turn. Spatial tuning ratio $=9.3$; speed tuning ratio $=6.1$ (minimum $n=184, \chi^{2}=336, d f=7, p<0.001$ ); direction tuning ratio $=$ 3.0 (minimum $n=52, \chi^{2}=49.0, d f=7, p<0.001$ ), turn tuning ratio $=3.4$ (minimum $n=15, \chi^{2}=18.5, d f=7, p<0.02$ ). $D$, This cell had 2 distinct subfields with different tuning parameters for each. In the subfield designated $X$, its firing rate gradually increased with faster movements, and the cell distinctly preferred movement in the SSE direction, with a coarse tuning to straight ahead. In the subfield designated $Y$, its firing rate increased sharply at an intermediate speed, and here the cell strongly preferred movement in the NNW direction, with a preference for turning sharply left. Spatial tuning ratio $=4.1$; subfield $x$ : speed tuning ratio $=3.1$ (minimum) $n=136, \chi^{2}=513, d f=7, p<0.001$ ); direction tuning ratio $=4.4$ (minimum $n=124, \chi^{2}=265, d f=7, p<0.001$ ), turn tuning ratio $=2.7$ (minimum $n=62, \chi^{2}=47.8, d f=7, p<0.001$ ); subfield $y$ : speed tuning ratio $=5.1$ (minimum $\left.n=54, \chi^{2}=122, d f=7, p<0.001\right)$; direction tuning ratio $=6.3\left(\right.$ minimum $n=22, \chi^{2}=46.9, d f=7, p$ $<0.001$ ), turn tuning n.s.; the cell fired time-locked to the approach to cup $1(4.6: 1)$ and cup $3(6.8: 1)$.

with maximal firing was seldom the same for a cell across different subfields (e.g., Fig. $6 D$ ). The mean tuning ratio for speed was 3.8:1 (Fig. $7 B$, left).

Direction. Cells in 187 (64\%) of all subfields considered had significant directional tuning. All directions were represented in substantial numbers, although some directions were represented disproportionately (Fig. $7 A$, center). The direction associated with maximal firing usually varied between subfields of the same cell (e.g., Fig. $6 D$ ). The mean tuning for direction was 4.3:1 (Fig. $7 B$, center).

Turning angle. Cells in 137 (47\%) of subfields had significant angular tuning. For the majority of subfields, the preferred angle was a small deviation from straight ahead (Fig. 7A, right). Preferred turning could vary between subfields of the same cell 
SPEED

\section{A. DISTRIBUTION OF OPTIMAL TUNING}

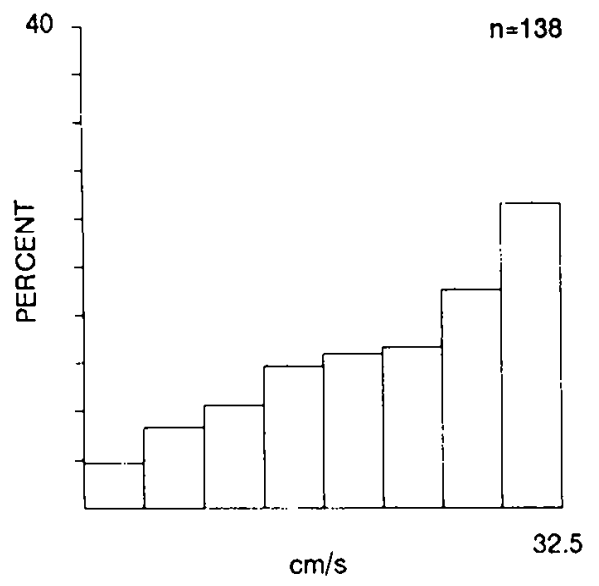

B. DISTRIBUTION OF TUNING SENSITIVITY

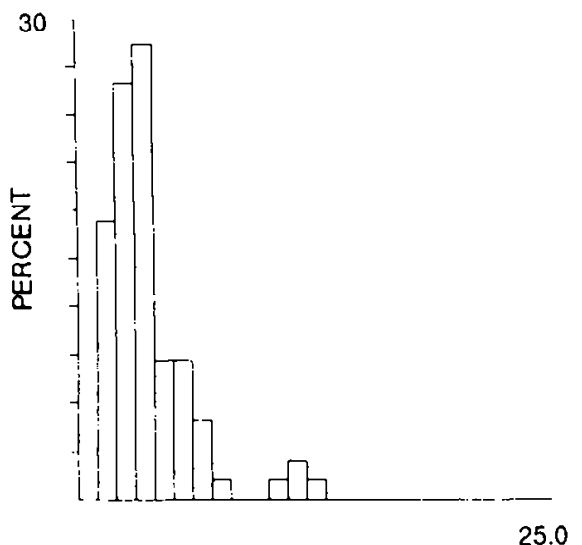

DIRECTION
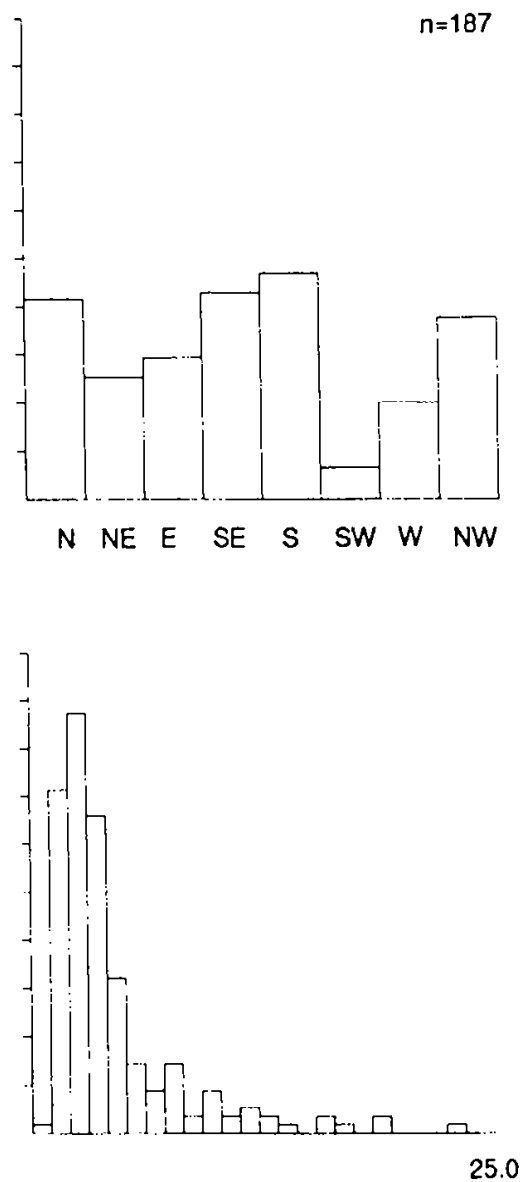

MAXIMUM/MINIMUM INFIELD FIRING RATE
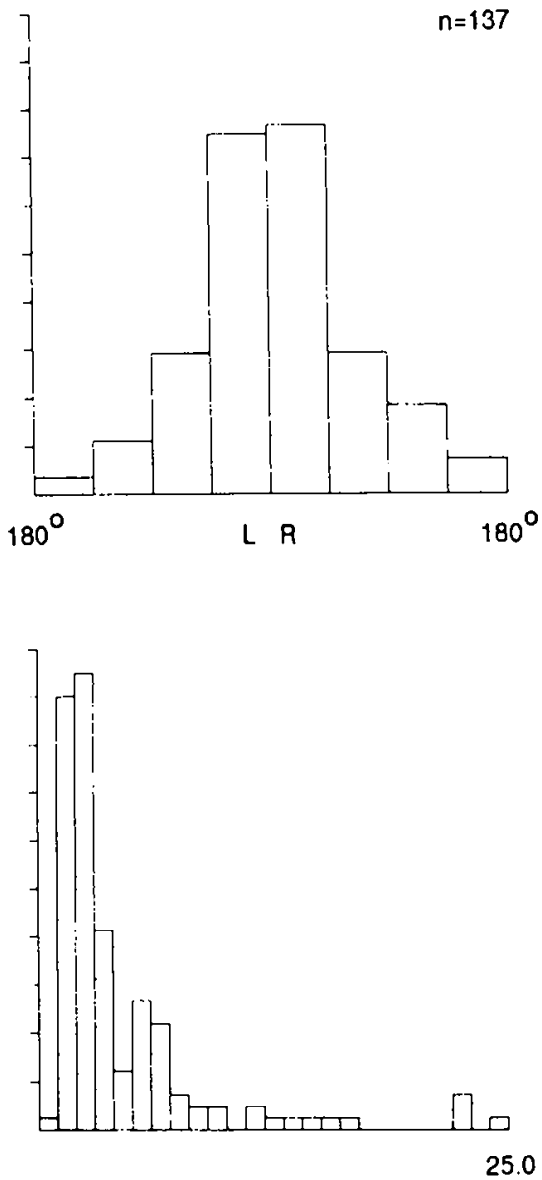

25.0

Figure 7. Normative data on the tuning for speed, direction, and turning angle in all subfields. These analyses include only those cases where there were statistically significant differences of firing rate associated with the appropriate variable. $A$, Distribution of the optimal value of movement tuning, defined as that movement speed, direction, or turning angle associated with maximal firing rate. $B$, Distribution of tuning sensitivity, measured as the ratio of the maximal firing rate versus the minimal nonzero firing rate in the tuning curves.

(e.g., Fig. 6D). The mean tuning to turning angle was 4.4:1 (Fig. $7 B$, right).

Unit activity time-locked to approach movements. Of all 415 cells recorded, $311(75 \%)$ met the criterion for activity timelocked to the approach to at least one reward cup. The mean ratio of maximum firing versus the average rate was $6.8: 1$. In almost every case, the time when synchronization occurred and the location of the place field for that cell were consistent (see examples below). Some cells had significant time-locked firing but no significant place field, although, in almost every case, the highest firing rate was observed in pixels near the cup associated with the time-locked activity.

Each of the examples of these analyses given in Figure 6 show that neuronal activity can be described either in terms of a place field or in terms of a combination of movement correlates and time-locked firing. The most complete account in each case is obtained by including both the spatial and behavioral correlates, and significant aspects of the functional correlate would be absent if either the spatial or behavioral determinants of firing were ignored. In the case shown in Figure $6 A$, the cell had a single place field near the center of the arena. This cell was highly tuned to near-maximal movement speed, direction "northnorthwest," and turning slightly to the right. Also, its activity was sharply time-locked to the approach to cup number 1 at the NE corner. Hence, one description of this cell's correlate is that it fired maximally as the rat made a rapid northwest movement and a right turn at the initiation of its approach to cup number 1. Describing this cell as a place cell with its field in the center is entirely compatible with, and is made more precise by adding the description based on movement variables. Similarly, the cell shown in Figure $6 B$ can be described as a place cell with its place field near the corner at cup number 2 , but it can be described more precisely if one includes the observation that the cell bursts when the rat makes a rapid, east-southeast, left-turning approach to cup number 2 .

Some cells showed significant time-locked firing to multiple events. For example, the cell shown in Figure $6 C$ had a place field in the arena center and fired on the initial approach to all 
A
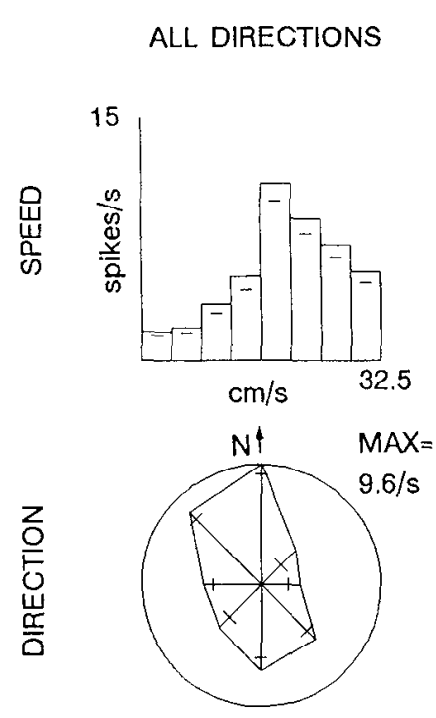

B

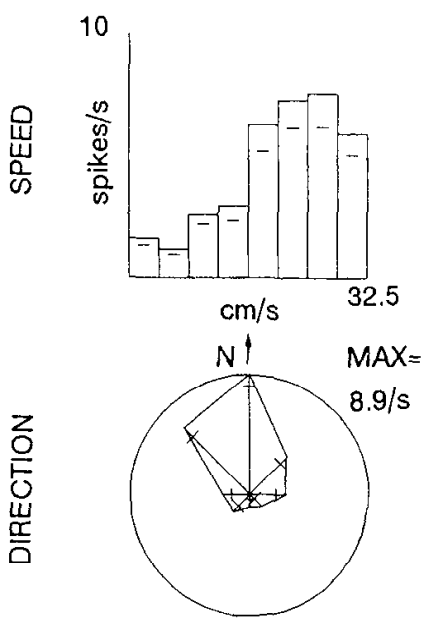

PREFERRED DIRECTION
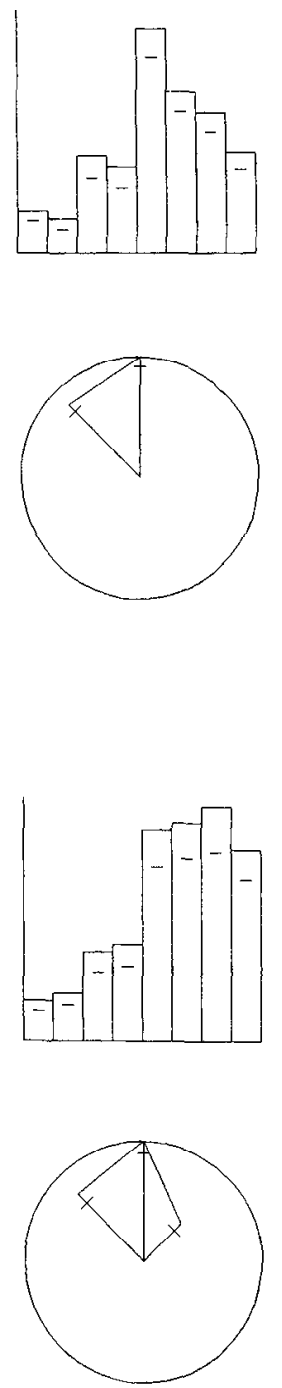

NON-PREFERRED DIRECTION
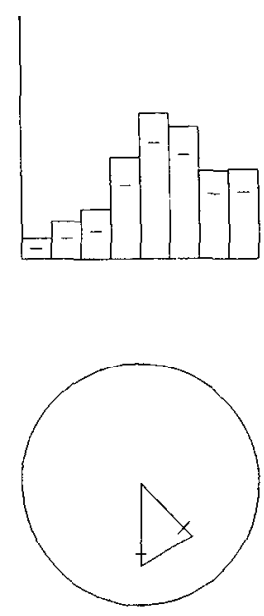

Figure 8. Comparisons of speed tuning for movements in directions associated with high and low firing rates. $A$, Left panel contains data shown in Figure $6 \mathrm{C}$. The tuning to movements at speeds at $24-28 \mathrm{~cm} / \mathrm{sec}$ is also found if only the preferred directions of NW and $\mathrm{N}$ are considered (middle panel, tuning ratio $=7.6$, minimum $n=70, \chi^{2}=122$, $d f=7, p<0.001)$. For the nonpreferred directions of SE and S (right panel), the cell is tuned to speed in a similar pattern (tuning ratio $=6.7$, minimum $n=40$, $\left.\chi^{2}=33.5, d f=7, p<0.001\right) . B$, In data from Figure $6 A$, the speed tuning found with movements in all directions (left ) is preserved for movements in the best directions of NW, N, and NE (middle, tuning ratio $=5.9$, minimum $n=$ 96, $\chi^{2}=147, d f=7, p<0.001$ ). At nonpreferred directions (SE, $S$, and SW), the firing rates for all speeds are very low. cups, with a preference for the approach to cup number 1 , a selectivity that could not have been anticipated from the locus of the place field. The cell shown in Figure $6 D$ had time-locked firing to cups 1 and 3, with opposing directional firing in separate subfields near those cups. Our examination of the oscilloscope traces of action potentials from this unit indicate a unitary waveform and good signal-to-noise ratio $(3: 1)$, consistent with the conclusion that the recordings were made from a single cell. On the other hand, methods other than those used here have becn able to separate cells that appear to have unitary waveform on a single electrode (McNaughton et al, 1983a). Since nothing less than intracellular recording would prove whether these units are single cells, no definitive conclusion that dual place fields and opposing movement correlate profiles were derived from a single neuron is possible. If, however, these data do indeed derive from a single neuron, it appears that some cells fire with mirror-image correlates, both in terms of the place field locus and in terms of the movement correlate profile. If the data were from 2 different cells, the findings would be just as interesting: some neighboring cell-pairs represent mirror-image place fields and movement correlates. In either case, a complete account of cellular activity benefits by considering both location and movement variables.

Finally, in a previous study of speed and directional tuning in place cells, McNaughton et al. (1983b) reported that hippocampal complex spike cells increased firing monotonically with movement speed as the rat ran along arms of a radial arm maze. Since the present findings show that many cells have nonmonotonic speed tuning curves, further analyses were focused on whether nonmonotonic speed tuning was a consequence of undersampling of high-speed movements in the preferred direction. In each case where speed tuning curves were constructed only for the optimal direction, the function remained nonmonotonic, and the tuning ratio could even be improved (Fig. 8). 


\section{A. PORT APPROACH}

$16 / s$
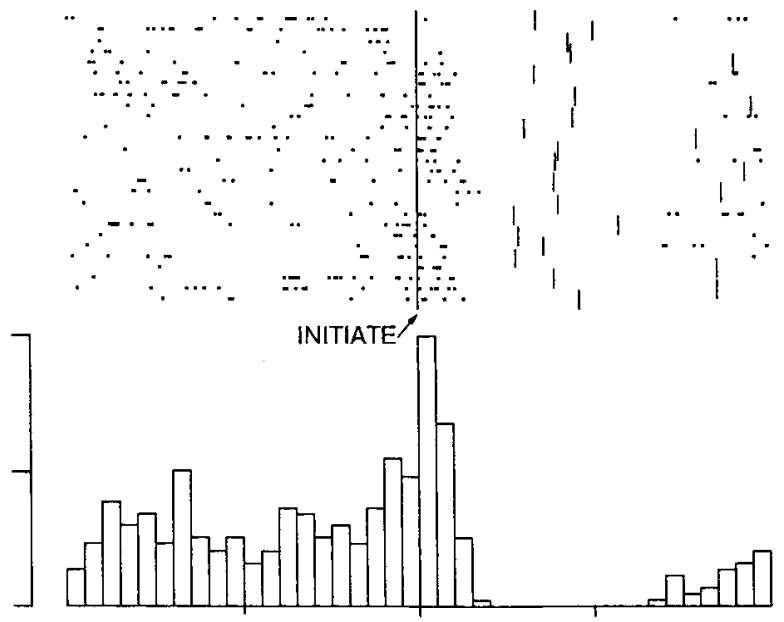

B. CUE-SAMPLING

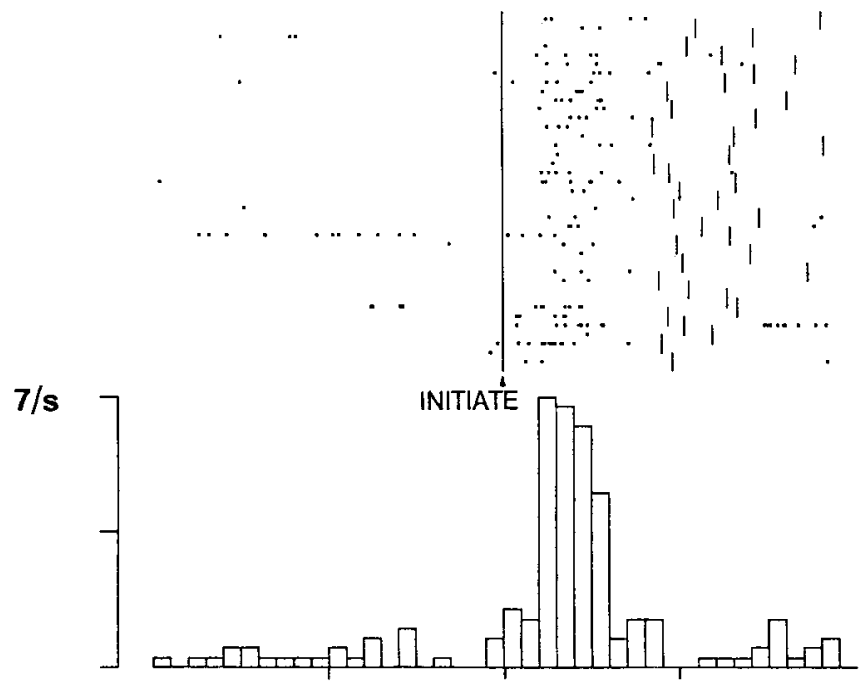

\section{CUP APPROACH}

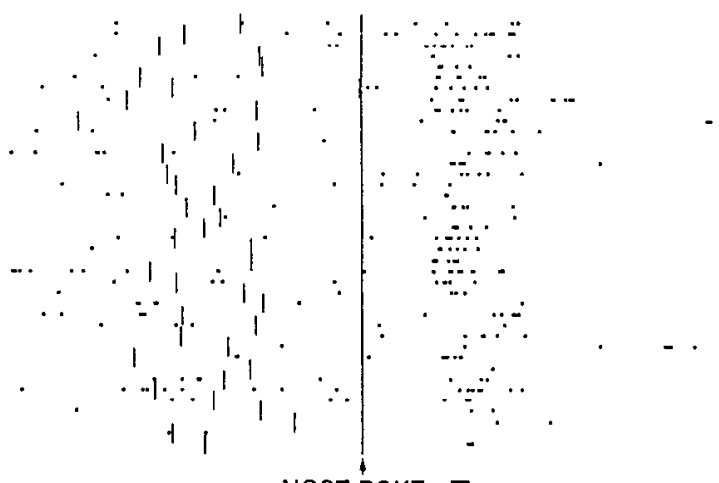

$14 / \mathrm{s}$

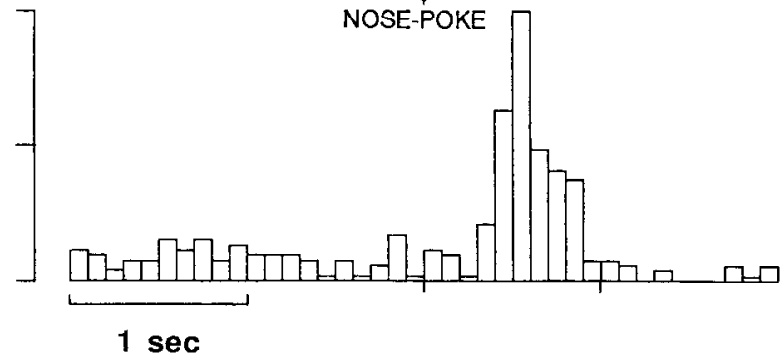

Under the conditions of the present paradigm, it appears that the firing rate of most cells is optimally tuned to a specific speed of movement.

\section{Odor task}

\section{Behavioral and spatial correlates}

Of 281 cells recorded in 8 rats during 69 sessions, $162(58 \%)$ had significant increases in firing rate during at least one of the defined intervals: cue-sampling, port-approach, and cup-approach. As can be seen by comparing examples from each of these categories (Fig. 9), each cell type fires during a discrete interval of the trial. The details of each of these behavioral correlates are described below.

Cue-sampling cells. The activity of cue-sampling cells usually synchronizes well to trial initiation (e.g., Fig. $9 B$ ) and to the nose-poke (e.g., Fig. 10A). Spatial analyses showed that these cells fired maximally as the rat approached the ports prior to the nose-poke (e.g., Fig. 10). These cells ceased firing upon the nose-poke to either port, with little further firing even as the rat passed through the same places where firing was maximal during odor sampling.

Some cue-sampling cells fired only while the rat was at each port. For example, in the case shown in Figure 11, the cell fired when the rat was sampling odors at each port but did not fire when the rat was moving between the two ports (Fig. 11A). Firing continued for $200 \mathrm{msec}$ after the nose-poke was initiated, while the rat's nose was still in the port, resulting in a bimodal envelope of unit activity continuing through the nose-poke (Fig. $11 B)$.

About half of the cue-sampling cells increased firing to a greater extent when the rat was at one port rather than the other, while it was sampling one pair of odors rather than the other, or the interaction of both variables (Table 1). The analyses of a cell that fired selectively while the rat sampled odors at one of the ports are shown in Figure 12. This cell fired robustly before the rat executed a nose-poke to the left port (Fig. 12A), but only weakly before the rat executed a nose-poke at the right port (Fig. 12B). Spatial analyses of unit activity associated with left (Fig. 12C) and right (Fig. 12D) nose-pokes confirmed that this cell fired selectively while the rat sampled odors at each port, with greater unit activity when the rat was on the left. This cell demonstrated no significant differences in activity depending on the odor sampled. Across all 15 cue-sampling cells with significant differences in firing in relation to port position, 8 had higher firing while the rat sampled odors at the left port rather than the right port.

Of all cue-sampling cells tested, $13 \%$ fired differentially during sampling of a particular pair of odors. In the case shown in

Figure 9. Raster display analyses on examples of cells from each major functional category of cells in the odor discrimination task. Each raster line shows the time of occurrence of unit spikes as dots and the trial initiation and nose-poke as tic marks. The summary histogram is normalized to the maximal firing rate in a $100 \mathrm{msec}$ bin. $A$, The activity of this port-approach cell is synchronized to, and reaches firing maximally rate upon trial initiation $(t=4.0, d f=218, p<0.001)$. This cell's firing rate is reduced below background during odor sampling $(t=$ $-17.7, d f=221, p<0.001)$ and approach to the water $\operatorname{cup}(t=-17.2$, $d f=201, p<0.001)$. $B$, Here the activity of this cue-sampling cell has been synchronized to trial initiation. It fired maximally between this event and the nose-poke $(t=10.6, d f=149, p<0.001)$. $C$, The activity of this cup-approach cell is synchronized to and fires maximally after the nose-poke $(t=6.1, d f=80, p<0.001)$. 

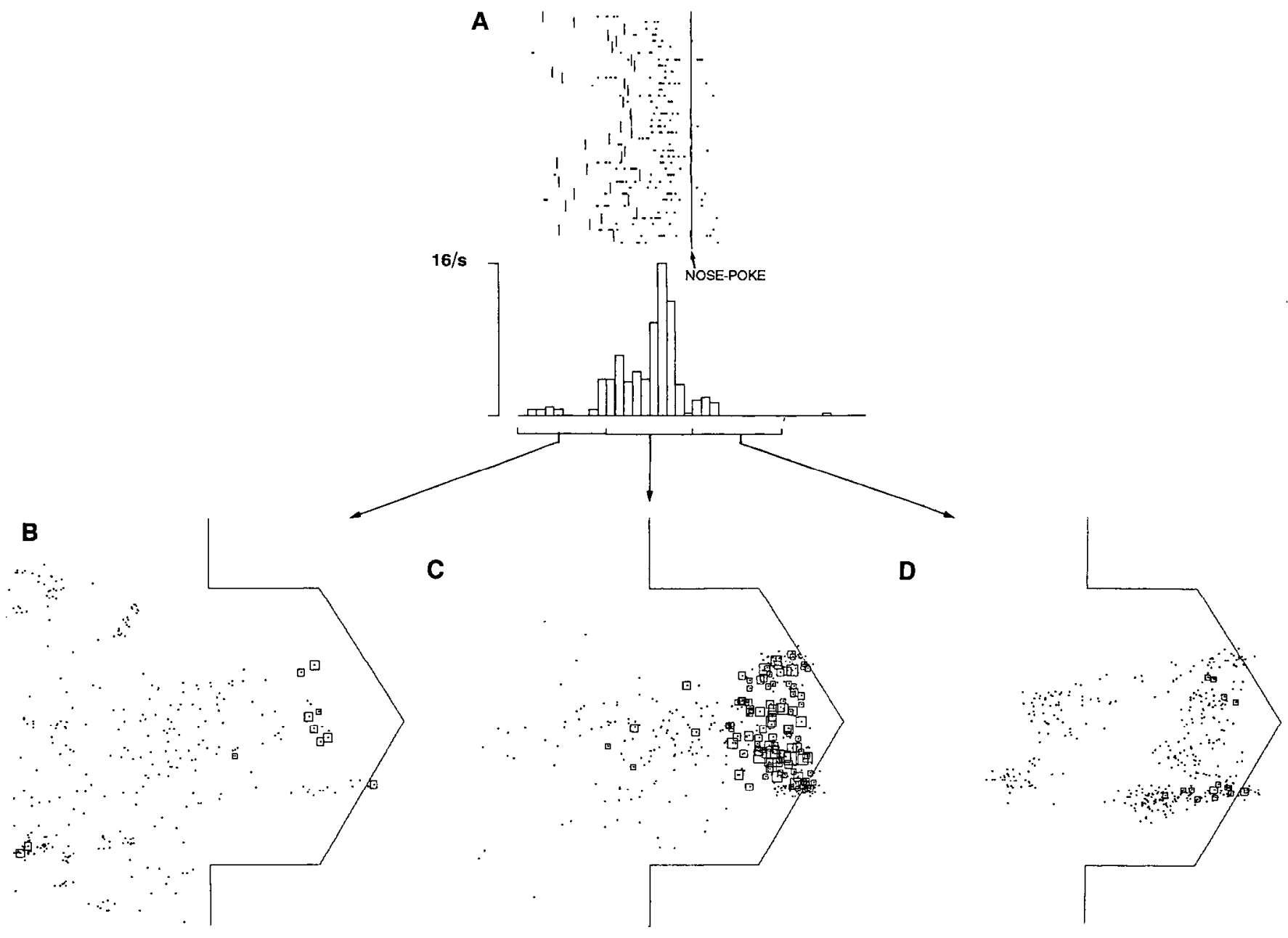

Figure 10. Analyses of the activity of a cue-sampling cell synchronized to the nose-poke. $A$, The raster display of this cell indicates maximal firing $200-500$ msec prior to the nose-poke $(t=15.1, d f=195, p<0.001) . B-D$, Spatial analyses show the location of the rat's head $(d o t s)$ and unit activity (squares of size proportional to firing rate) at $100 \mathrm{msec}$ intervals superimposed on a outline of the cul-de-sac during the $1 \mathrm{sec}$ trial periods indicated on the abscissa of the histogram above. $B$, The cell begins to fire as the rat approaches the ports. $C$, Maximal firing occurs as the rat samples odors before the ports. $D$, The cell ceases firing abruptly upon the nose-poke to either port.

Figure 13, the cell had a greater response while the rat sampled odor pair 1-2 than while it sampled odor pair 3-4. This cell also had a greater response when the $\mathrm{S}^{+}$was on the left rather than on the right for each odor pair, resulting in different response patterns among the configurations of odor pair and position.

In $11 \%$ of cue-sampling cells the response was statistically related to the interaction of odors and their positions. Indeed, some cells fired selectively as the rat sampled one particular odor configuration. In the case in Figure 14, the cell had a much greater response when the rat was sampling odor pair 1-2 when the $\mathrm{S}^{+}$was on the left than any of the other odor configurations. Firing during the odor sampling period was not dependent on odor quality alone, since the response during the sampling when odor 1 was on the right (Fig. 14B) was not as strong as when it was on the left (Fig. 14A). Nor was the firing simply position dependent since the response during the sampling of odor pair 3-4 when the $\mathrm{S}^{+}$was on the left (Fig. 14C) was not as strong as that for odor pair 1-2 with the $\mathrm{S}^{+}$in the same position (Fig. $14 A$ ), and the cell ceased firing in each case after the nose-poke even though the animal remained at the same locus (not shown).

Finally, almost all cue-sampling cells fired phase-locked to both the sniffing cycle and the theta rhythm. Figure 15 shows the distribution of spikes in relation to sniff and theta phase over the cue-sampling period for the cell whose analyses are presented in Figure 14. These distributions indicate that the cell prefers to fire at a particular phase of both the sniffing cycle and the theta rhythm, which are typically synchronized to each other during odor sampling (Macrides, 1975; Macrides et al., 1982).

Goal approach cells. Port-approach cells fired as the rat moved into the cul-de-sac to perform a discrimination trial (e.g., Fig. $9 A$ ). For the cell whose analyses are shown in Figure 16, firing was maximal just before the rat entered the cul-de-sac regardless of the point of origination or the path of movement (Fig. 16, $A, C$ ). The cell ceased firing during the odor sampling and response periods (Fig. 16, $A, D$ ). As might be expected, we found no port-approach cells that fired differentially in relation to response position or odor pair (Table 1).

Cup-approach cells fired either as the rat began to exit from either port following a nose-poke or along the movement path towards the water cup from either port. The analyses of one case are shown in Figure 17. The cell did not fire when the animal approached the ports prior to the nose-poke response (Fig. 17, $A, B, D, E$ ), but fired robustly as the rat withdrew from 


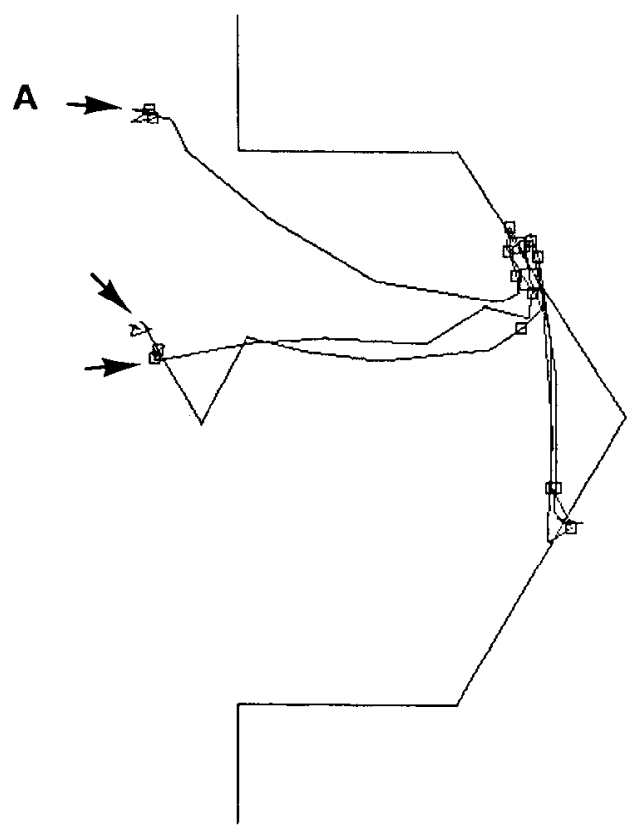

B

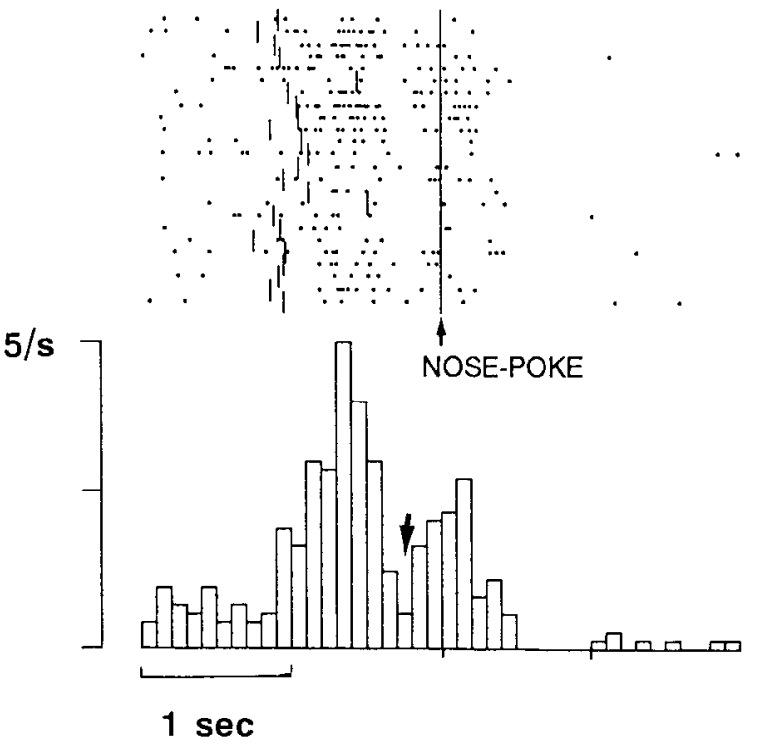

Figure 11. Analyses of a cue-sampling cell that fires only as the rat samples odors before each port. $A$, The spatial analysis indicates the movement trajectory for 3 trials ending in a correct nose-poke to the right port. The movement path for each trial is shown as a line beginning at each arrow. Note that the rat always approached the left port first, then approached and made the nose poke to the right port. $B$, The raster display synchronized to the nose-poke indicates 2 firing peaks during the odor sampling and response period $(t=14.3, d f=204, p<0.001)$. The period of reduced firing (arrow in histogram) corresponds to when the rat traversed the area between the 2 ports.

either port, at the same locations where it had not fired prior to the nose-poke (Fig. 17, $C, F$ ). Furthermore, the cell did not fire when the rat withdrew from the left port without exccuting a nose-poke, and then approached the right port (Fig. 17E). Many cup-approach cells fired preferentially after the rat had responded at one port or after the rat had sampled one of the odor pairs (Table 1).

Other unit responses. Six cue-sampling cells also had a significant elevation in firing during the cup approach, and 21 cells fired during both the port and cup approach. Both of these types of cells often had a significant firing decrease below the background rate during the interval between the 2 periods of increased firing. Other cue-sampling and goal-approach cells also had marked and significant firing rate reductions at some period during the trial (e.g., Fig. 9A). Among 119 cells (from the total of 281 recorded) with no significant firing increase, 101 had significantly decreased firing during part or all of the trial.

\section{Cells recorded in both the place task and odor task}

Data wcre collectcd from 97 cells in both the odor and place tasks. For comparative purposes, we considered as separate categories 3 main types of cells that were distinguished by their behavioral correlates in the odor task: cue-sampling cells, goalapproach cells, and cells that had no significant increase in firing rate associated with trial events. Cells in all 3 functional categories were very likely to have place fields and movement correlates in the spatial task (Table 2). The location of the place field was often distinct from the location associated with the functional correlate in the odor task. For example, the analysis of a cell that had a cue-sampling correlate in the odor-discrimination task is shown in Figure 18. This cell burst sharply 500$700 \mathrm{msec}$ after odor onset and prior to the discriminative response (Fig. 18A). A map of movements and locations of spike activity during the same period confirms that the cell fired pri-

Table 1. Summary of the results of statistical evaluations of unit activity in the odor task

\begin{tabular}{|c|c|c|c|c|c|}
\hline \multirow[b]{2}{*}{ Functional correlate } & \multirow[b]{2}{*}{$\begin{array}{l}t \text { Test } \\
(n=281)\end{array}$} & \multicolumn{4}{|c|}{ ANOVA } \\
\hline & & $n$ & Odor & Position & $\begin{array}{l}\text { Odor } x \\
\text { position }\end{array}$ \\
\hline Cue-sampling ${ }^{a}$ & 62 & 45 & 6 & 15 & 5 \\
\hline Port-approach & 37 & 20 & 0 & 0 & 0 \\
\hline Cup-approach $^{a}$ & 36 & 48 & 3 & 15 & 6 \\
\hline Multiple correlates & 27 & & & & \\
\hline
\end{tabular}

Column labeled $t$ Test gives the distribution of cells with a statistically significant increase in activity associated with each functional category. The number of cells analyzed by a $t$ test $(n)$ include all cells recorded. The numbers of cells analyzed by ANOVA $(n)$ include those cells that had a significant $t$ test and were recorded while rats performed the concurrent discrimination composed of 2 odor problems. Columns labeled ANOVA are the distributions of cells with a statistically significant difference in activity in relation to which odors were being sampled, the position of the odors, and the interaction of these 2 variables.

a For this analysis, cells with multiple correlates were tested in the ANOVA for effects in each of the appropriate intervals. 
A
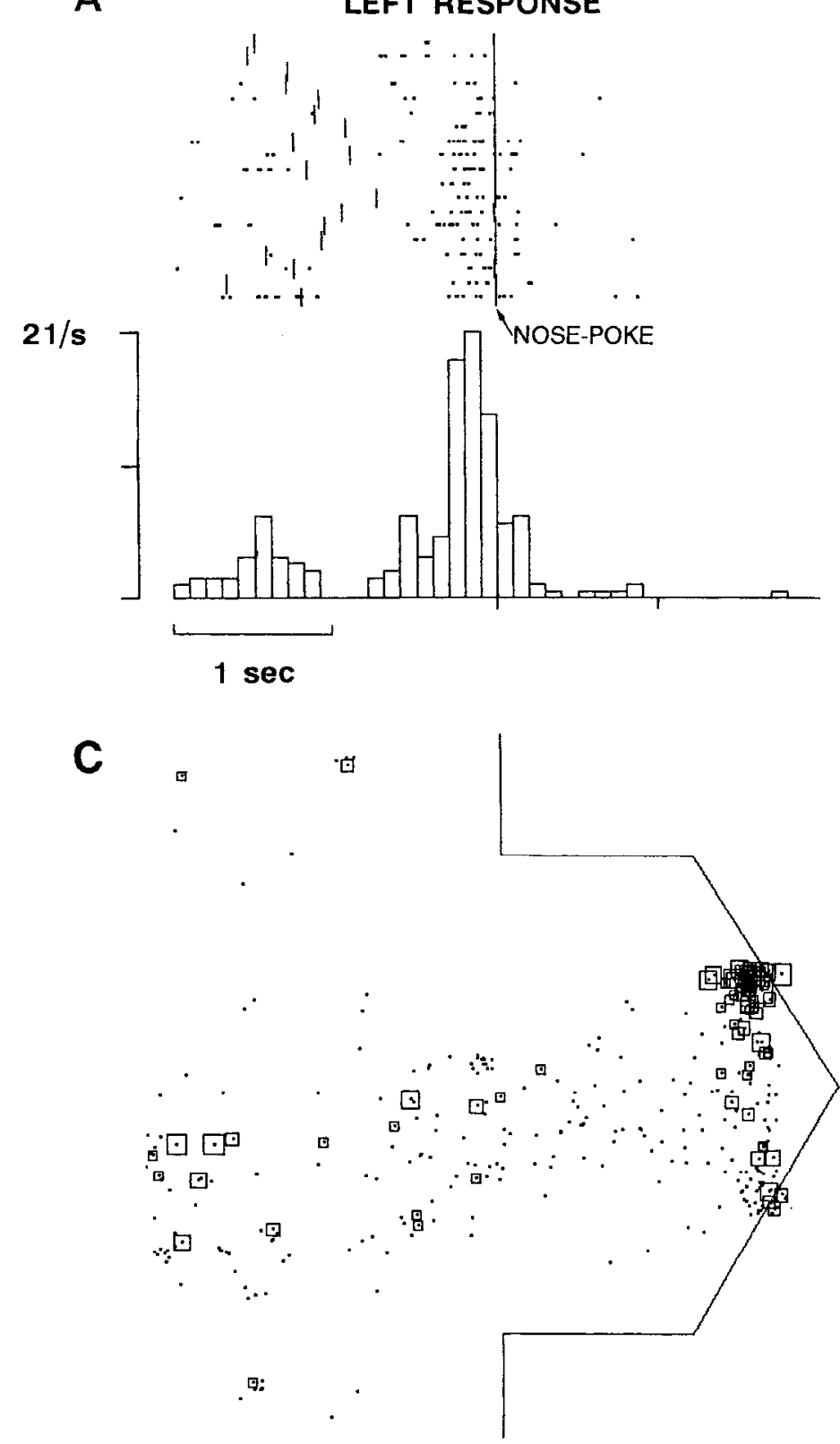
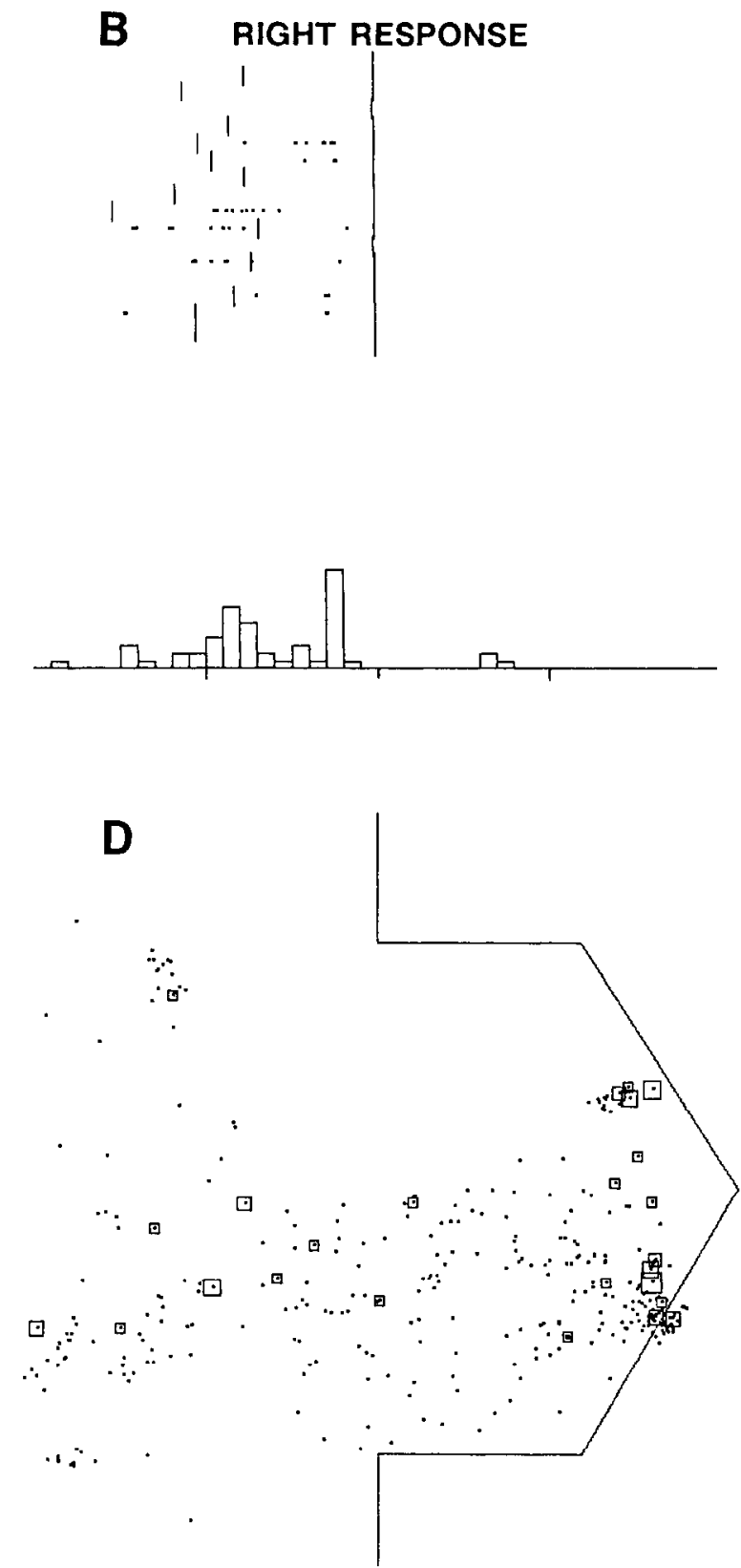

Figure 12. Analyses of a cue-sampling cell with a greater response as the rat samples the left port than the right port. Raster displays and spatial analyses synchronized to the nose-poke indicate a high firing rate just prior to the left nose-poke $(A, C)$ and a weak response prior to a right nosepoke $(B, D)$. Odor sampling period: $t=11.0, d f=230, p<0.001 ;$ ANOVA: $d f=218, F_{\text {position }}=9.38, p<0.005 ; F_{\text {odors }}=0.08$, n.s.; $F_{\text {interaction }}=$ 0.0 , n.s.

marily when the animal was between the sniff ports, where a decision about the response choice is made (Fig. 18B). In the place task, this cell had a distinct place field at the opposite end of the arena from the sniff ports and had significant speed and directional tuning. Furthermore, its activity was time-locked to approach behaviors (Fig. 18C). There was no obvious relationship between the functional correlates across the odor and place tasks.

The findings were similar for cells that had goal-approach correlates in the odor task. For example, as shown in Figure $19 \mathrm{~A}$, one of these cells fired sharply $300-600 \mathrm{msec}$ after the discriminative response, when the rat withdrew from the sniff port (Fig. 19B). In the place task, the cell had a place field near cup 1, outside the cul-de-sac, and fired in relation to movement variables and time-locked to the approach to cup 1 and, to a lesser extent, on the approach to cup 2 (Fig. 19C).

The distribution of place fields for cells from each odor-task category spanned the entire arena (Fig. 20). Thus, place fields for cells with cue-sampling and goal-approach correlates were not concentrated at the cul-de-sac, where these cells were selectively active during the odor task. Nor in any other way did the location of place fields consistently predict the odor-task correlate.

Comparing the relative activity of all cells recorded in both tasks, $82(85 \%)$ had a place field and $52(54 \%)$ had a reliable cue-sampling or goal-approach correlate in the odor discrimi- 
A. ODOR 1 LEFT/ODOR 2 RIGHT

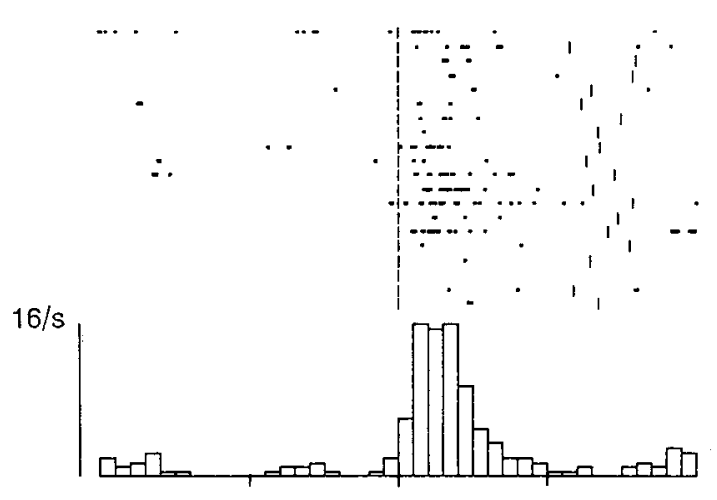

C. ODOR 3 LEFT/ODOR 4 RIGHT

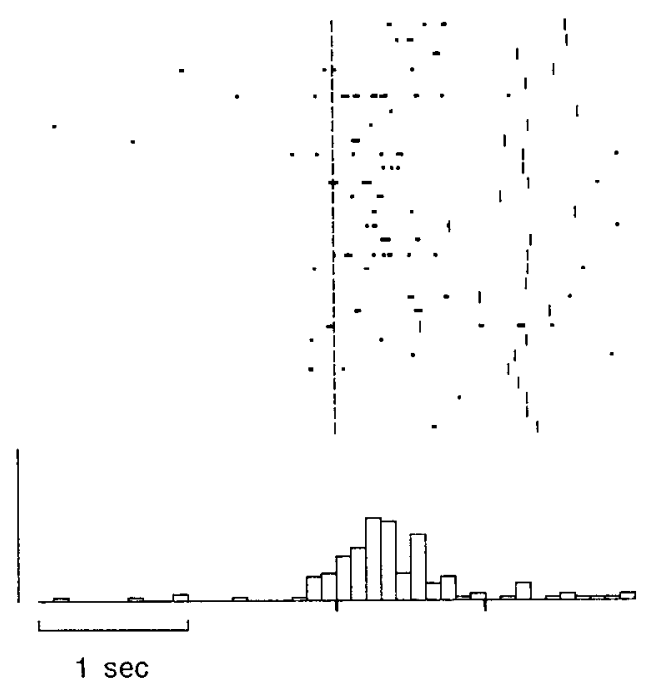

B. ODOR 2 LEFT/ODOR 1 RIGHT

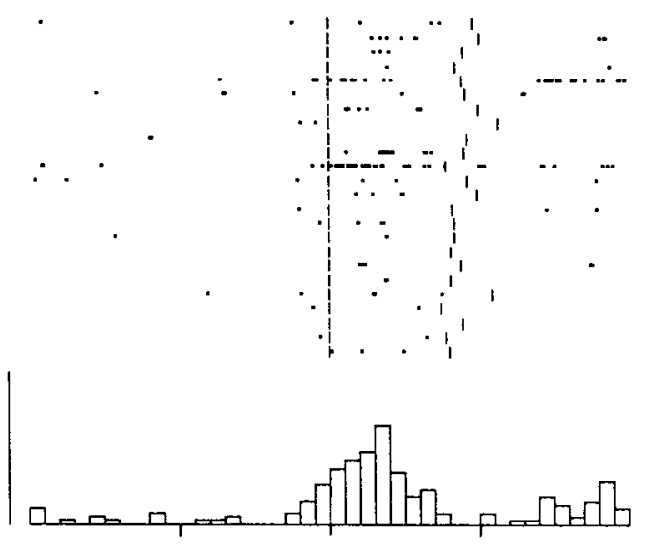

D. ODOR 4 LEFT/ODOR 3 RIGHT

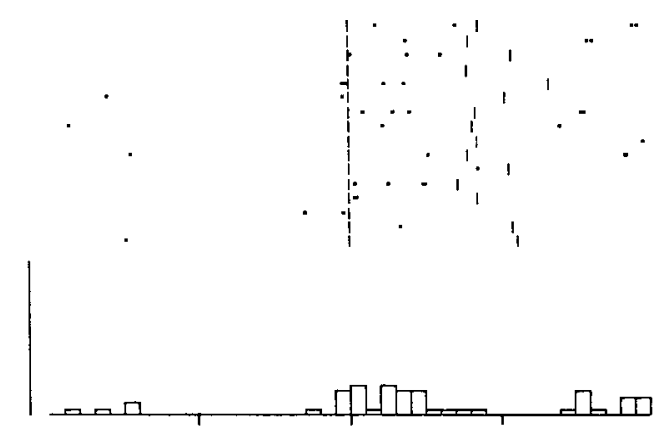

Figure 13. Analyses of a cue-sampling cell that has a greater response as the rat samples odors 1 and 2 and also when the $\mathrm{S}^{+}$odor (odor 1 or odor 3 ) is at the left port rather than the right. Odor sampling period: $t=5.8, d f=116, p<0.001$; ANOVA: $d f=85, F_{\text {odors }}=8.69, p<0.005 ; F_{\text {position }}$ $=7.52, p<0.005 ; F_{\text {interaction }}=0.05$, n.s.

nation task. Although a majority of cells from all odor-task categories had a place field in the place task, fewer cue-sampling cells had place fields than goal-approach cells or cells with no increase in firing in the odor task $\left(\chi^{2}=7.6, d f=2, p<0.05\right)$. Furthermore, the size of place fields for cue-sampling cells (mean $=16$ pixels) was smaller than that of goal-approach cells (mean $=33$ pixels; $t=3.68, d f=46, p<0.01$ ) or cells with no increase in firing (mean $=33$ pixels; $t=5.91, d f=69, p<0.001$ ). The incidence of significant speed, direction, and angular tuning was similar among odor-task categories (see Table 2).

In order to test which task better engaged neuronal activity, the average firing rates were computed for each task on all cells. The distributions of average firing rates were very similar across the 2 tasks and for both types of cells active in the odor task: In the place task, $29 \%$ of cells had average firing rates under $1 / \mathrm{sec}, 60 \%$ under $4 / \mathrm{sec}$, and $83 \%$ under $10 / \mathrm{sec}$. The mean outof-field firing rate was $3.3 / \mathrm{sec}$. For firing rates in the odor task, $23 \%$ of cue-sampling cells fired at less than $1 / \mathrm{sec}, 54 \%$ below $4 / \mathrm{sec}$, and $73 \%$ below $10 / \mathrm{sec} ; 19 \%$ of goal-approach cells fired below $1 / \mathrm{sec}, 54 \%$ below $4 / \mathrm{sec}$, and $83 \%$ below $10 / \mathrm{sec}$. However, as shown in Table 3, cells for which a behavioral correlate could be identified in the odor task tended to have a higher average firing rate in the odor task than the place task, as compared with cells with no increase in firing in the odor task $\left(\chi^{2}=10.21, d f\right.$ $=2, p<0.01$ ).

Finally, we attempted to determine whether each cell with an odor-task corrclate was better "tuncd" to behavioral events in the odor task or to location in the place task. We chose to compare maximum firing rates (normalized to background) of the odor-task correlate versus that of the place correlate, even though these basic correlates alone do not explain all the variability of firing rate in either task. While the maximum firing rates in both tasks theoretically could be improved by considering other variables, significant effects of all the appropriate variables could not be demonstrated in a sufficient number of cells. In the specific examples shown above (Figs. 18, 19), the maximum firing rate in both cases was achieved during the behavioral correlate in the odor task. Our analyses of the entire set of cells evaluated in both tasks indicated that cells with cuesampling and goal-approach correlates differed in the degree to which they were "tuned" to behavioral correlates in the odor task versus to place fields in the place task (Table 4). Thus, most cue-sampling cells increased firing more during odor sampling than when the rat was in the place field in the spatial task. 


\section{A. ODOR 1 LEFT/ODOR 2 RIGHT}

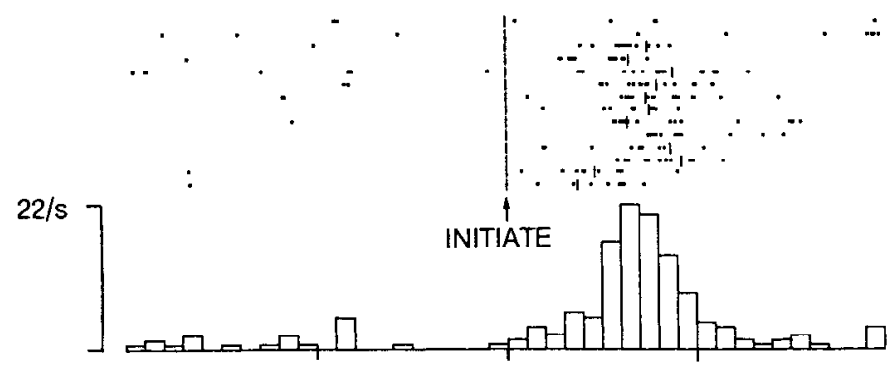

C. ODOR 3 LEFT/ODOR 4 RIGHT
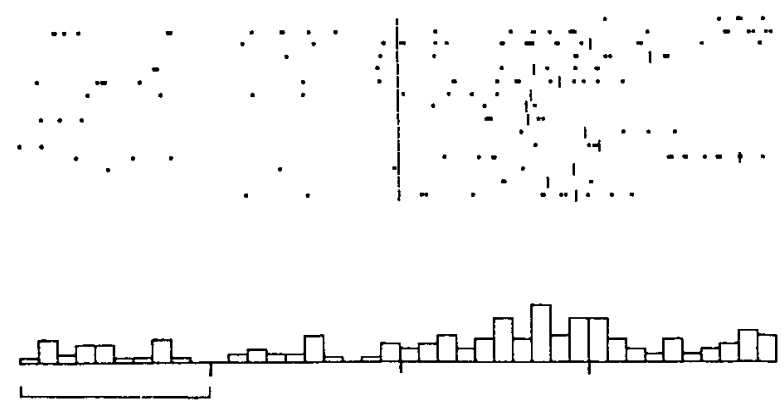

B. ODOR 2 LEFT/ODOR 1 RIGHT
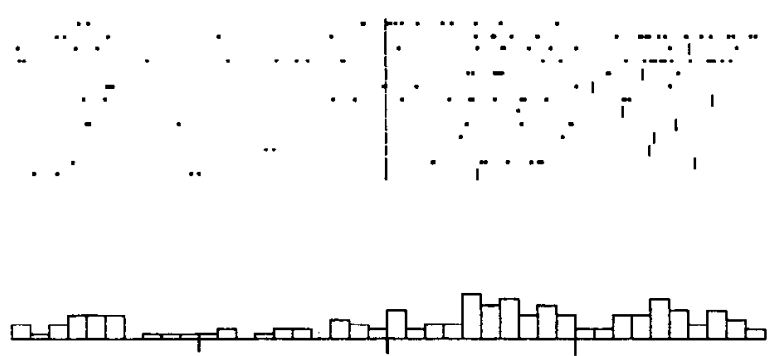

D. ODOR 4 LEFT/ODOR 3 RIGHT
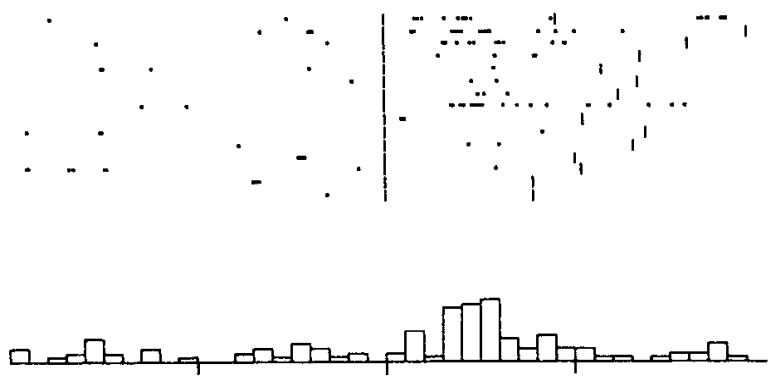

Figure 14. Analyses of a cue-sampling cell that fires maximally as the rat samples a particular odor configuration. This cell's activity is synchronized to the trial initiation, and it fires maximally just prior to the nose-poke when odor 1 is presented on the left and odor 2 is on the right $(A)$, rather than the other configuration of the same odors $(B)$ or either configuration of another odor pair $(C, D)$. Odor sampling period: $t=13.8, d f=254$, $p<0.001 ;$ ANOVA: $d f=220, F_{\text {position }}=17.07, p<0.005 ; F_{\text {odors }}=1.66$, n.s.; $F_{\text {interaction }}=8.44, p<0.005$.

Conversely, most goal-approach cells increased firing more when the rat was in the place field than when the rat was performing the approach behavior in the odor task. The difference between cell types was significant $\left(\chi^{2}=9.12, d f=1, p<0.01\right)$.

\section{Discussion}

The present survey of the behavioral physiology of hippocampal complex spike cells generated 3 main findings on the functional correlates of their activity. (1) Most cells have place fields as rats perform a spatial navigation task in an enclosed arena. The firing rate of these cells is not determined by location alone; rather, firing also depends on ongoing spatial behavior. (2) The

Table 2. Incidence of place fields and movement correlates in the place navigation task for cells with different functional correlates in the odor task

\begin{tabular}{lcll} 
& \multicolumn{3}{l}{ Type of odor-task correlate } \\
\cline { 2 - 4 } & $\begin{array}{l}\text { Cue- } \\
\text { sampling } \\
(\%)\end{array}$ & $\begin{array}{l}\text { Goal- } \\
\text { approach } \\
(\%)\end{array}$ & $\begin{array}{l}\text { No in- } \\
\text { crease } \\
\text { in firing } \\
(\%)\end{array}$ \\
\hline Number with place field & $20(69)$ & $21(91)$ & $41(91)$ \\
Number without place field & $9(31)$ & $2(9)$ & $4(9)$ \\
Speed & $12(41)$ & $16(65)$ & $29(58)$ \\
Direction & $13(45)$ & $15(61)$ & $35(71)$ \\
Angle & $10(34)$ & $12(48)$ & $25(53)$
\end{tabular}

For movement variables, pcrecntages refer to the number of cells in the appropriate category that had a place field.

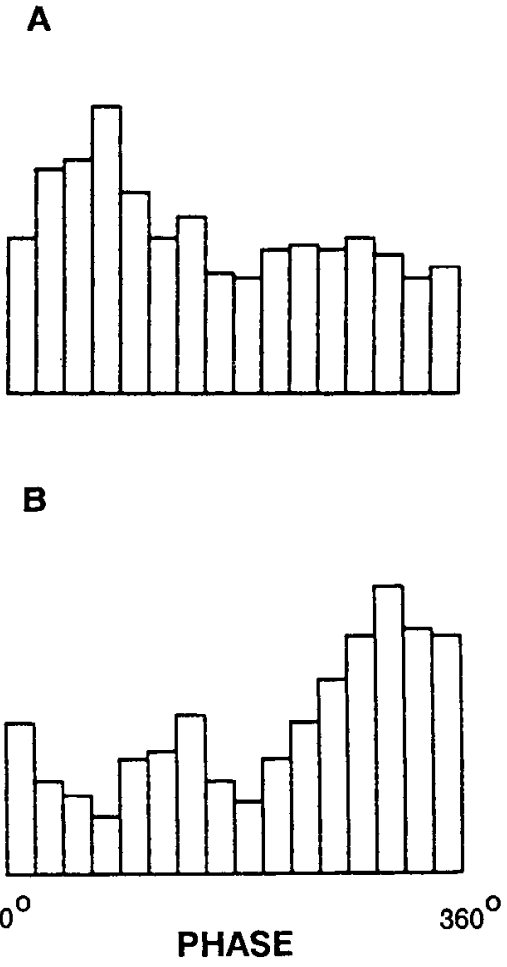

Figure 15. The relationship of unit activity to the sniff cycle and theta rhythm. The distribution of spikes for the cue-sampling cell whose analyses are shown in Figure 14 are plotted as a function of phase for sniff and theta cycles as described in Materials and Methods. The cell was optimally tuned to $90^{\circ}$ in the sniff cycle $(r=0.7, p<0.01)$ and to $315^{\circ}$ in the theta cycle $(r=0.8, p<0.001)$. 


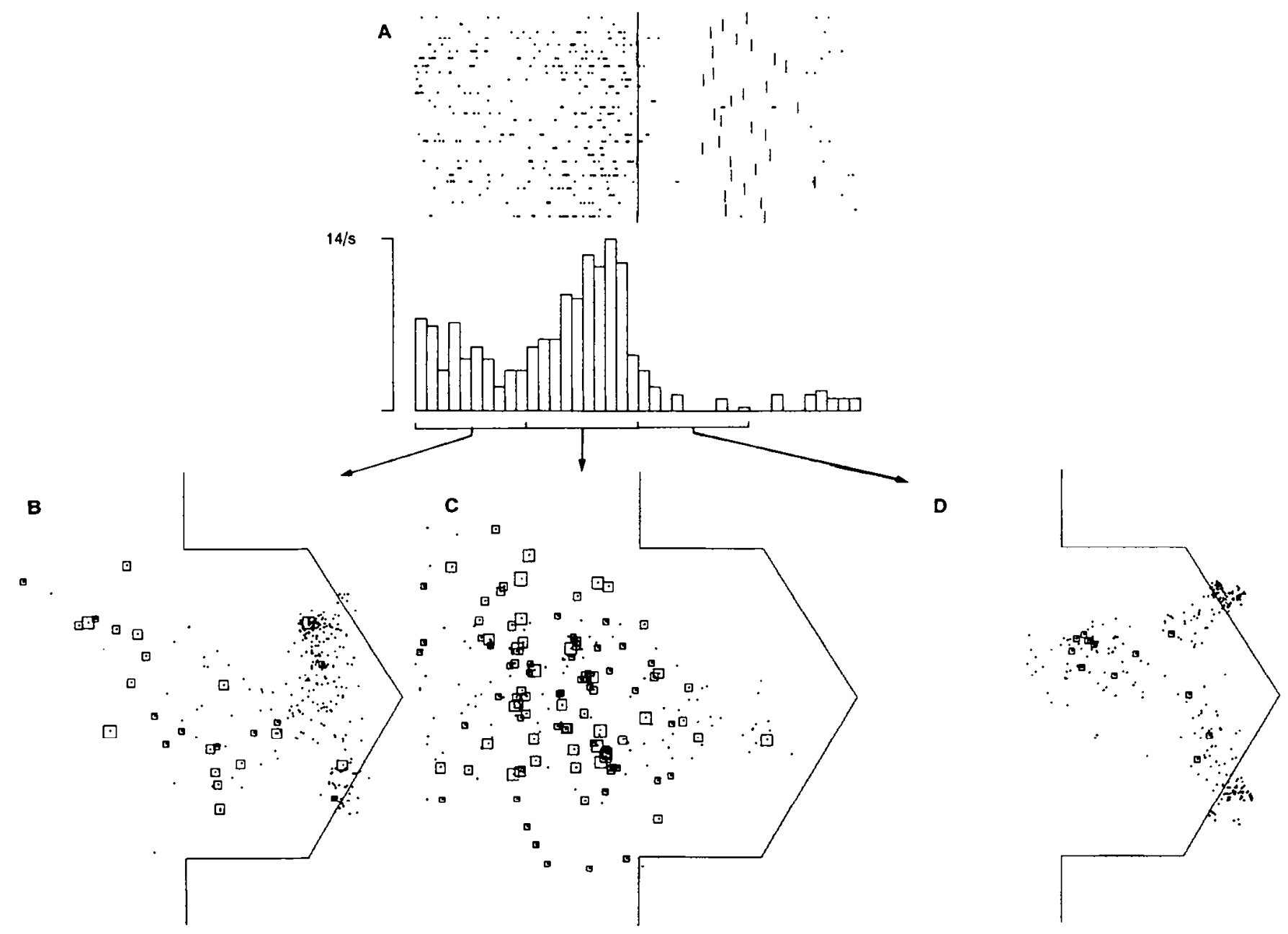

Figure 16. Analyses of a port-approach cell. $A$, The raster display synchronized to the trial initiation indicates that the cell reached maximal firing reliably just prior to the entry into the cul-de-sac $(t=7.3, d f=110, p<0.001) . B-D$, Spatial analyses for 1 sec trial periods indicated above in $A$ show considerable spatial dispersion in the approach movements and in the firing locus prior to the trial initiation $(B-C)$ and minimal firing after trial initiation $(D)$.

majority of cells have striking behavioral correlates as rats perform an odor-discrimination task. These correlates are incompletely predicted by the location of the animal when the behavior is executed, but relevant spatial factors contribute to a complete description of the behavioral correlate in many cells. (3) The same cells often have striking and seemingly unrelated spatial correlates in the place task and behavioral correlates in the odor task, although different cell types, as distinguished by their odortask correlates, are differentially engaged by the 2 tasks. Each of these general conclusions and their implications about hippocampal function will be discussed below.
Spatial and behavioral correlates of hippocampal unit activity in place tasks

The present results show that most CAI complex spike cells have place fields when rats perform an automated spatial navigation task in an enclosed environment. Furthermore, our normative data on a large number of single neurons indicated that three-quarters of these cells, over a large range of firing rates, fire in relation to spatial location as defined by measures of statistical reliability and that there is considerable variability in the degree of spatial "tuning." These data are similar to reports

Table 3. Incidence of cells with higher average firing rates in the place task or the odor task (excluding ties)

Type of odor-task correlate

\begin{tabular}{llll} 
& \multicolumn{3}{l}{ Type of odor-task correlate } \\
\cline { 2 - 4 } & $\begin{array}{l}\text { Cue-sampling } \\
(\%)\end{array}$ & $\begin{array}{l}\text { Goal-approach } \\
(\%)\end{array}$ & $\begin{array}{l}\text { No increase } \\
\text { in firing } \\
(\%)\end{array}$ \\
\hline Number with greater rate in odor-task & $19(68)$ & $18(82)$ & $19(43)$ \\
Number with greater rate in place-task & $9(32)$ & $4(18)$ & $25(57)$
\end{tabular}


Time-lock to nose poke

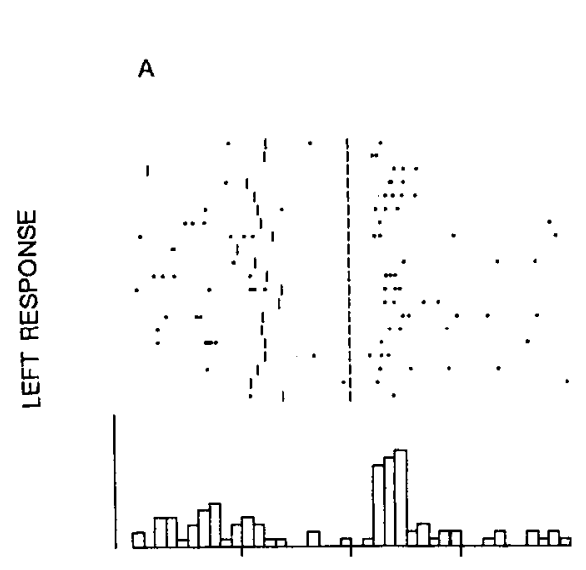

Prior to nose poke
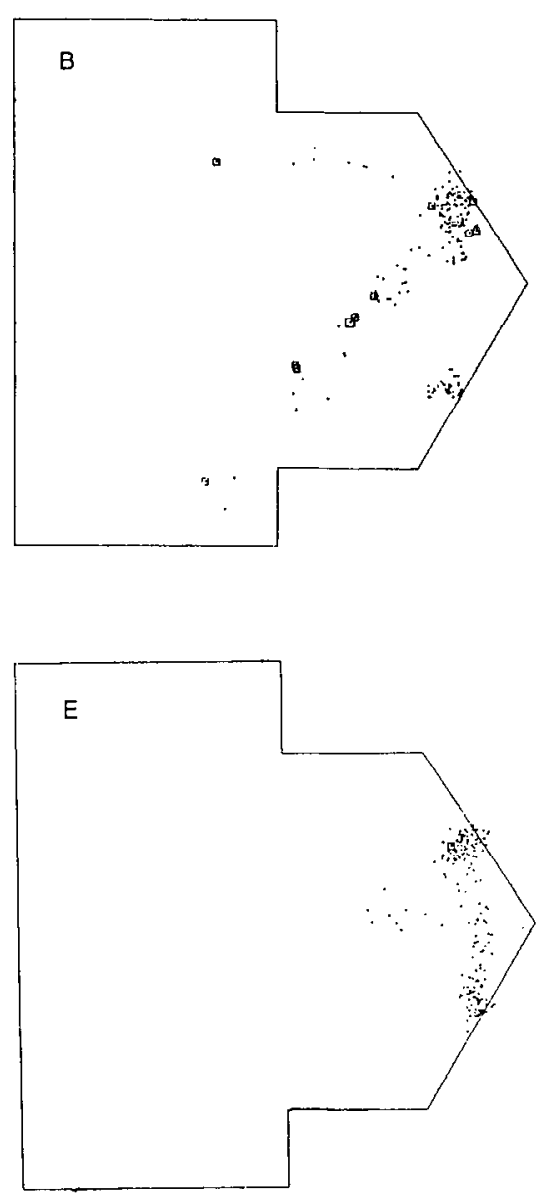

After nose poke
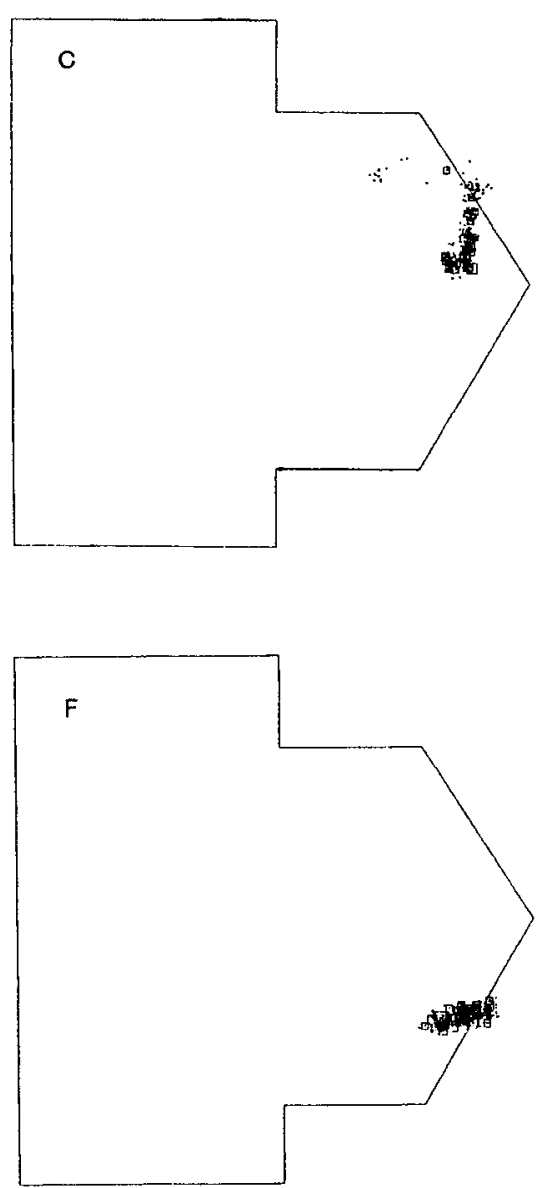

Figure 17. Analyses of a cup approach cell. Raster displays indicated maximal firing just after the nose-poke $(t=7.6, d f=186, p<0.001)$, with greater activity after a nose-poke to the right port than to the left (ANOVA: $d f=234, F_{\text {position }}=16.70, p<0.005 ; F_{\text {odors }}=0.45$, n.s.; $F_{\text {interaction }}=$ 0.27 , n.s.). Spatial analyses indicate little unit activity when the rat is at the ports for 1 sec prior to the nose-poke $(B, E)$ but considerable activity when the rat passes through the same loci at either port just after the nose-poke $(C, F)$.

of hippocampal place fields in a wide range of tasks, including multi-arm mazes (O'Keefe, 1976; Hill, 1978; Miller and Best, 1980; Hill and Best, 1981; McNaughton et al., 1983b; O'Keefe and Speakman, 1987), enclosed fields (Kubie and Ranck, 1983; Eichenbaum et al., 1987; Muller et al., 1987; Muller and Kubie, 1987), operant chambers (Kubie and Ranck, 1983), and open fields (O'Keefe and Conway, 1978; Christian and Deadwyler, 1986). In the present experiment, the place fields of single neurons were often composed of multiple "subfields," another finding that is consistent with other reports of distinct subfields in single cells isolated by refined methods of unit discrimination (Muller et al., 1987; O'Keefe and Speakman, 1987). Thus, the cells studied here may be considered to have the same basic spatial firing characteristics as "place cells" described elsewhere. Furthermore, the parameters accounting for spatial firing in the present experiment can be compared usefully with those of other descriptions of hippocampal place cells. Other observations in the present study are focused on whether the fundamental coding property of these cells is spatial location, that is, to what extent place versus other spatial and nonspatial variables account for neuronal activity.

\section{Dependence of infield firing rate on behavior during spatial navigation}

Location did not account for all of the activity of a cell when the rat was in the place field, nor was place the only reliable predictor of firing in hippocampal cells as rats performed a spatial-navigation task. The present results indicate that at least

Table 4. Best functional correlate of cells with an odor-task correlate (excluding ties)

\begin{tabular}{lll} 
& \multicolumn{2}{l}{$\begin{array}{l}\text { Type of odor- } \\
\text { task corrclate }\end{array}$} \\
\cline { 2 - 3 } & $\begin{array}{l}\text { Cue- } \\
\text { sampling } \\
(\%)\end{array}$ & $\begin{array}{l}\text { Goal- } \\
\text { approach } \\
(\%)\end{array}$ \\
\hline Number with better odor-task correlate & $20(77)$ & $6(29)$ \\
Number with better place-task correlate & $6(23)$ & $15(71)$ \\
\hline
\end{tabular}

Comparisons were based on the ratio of the peak to pretone firing rate during the odor task versus the ratio of the maximum infield to average out-of-field firing rate during the place task. 
A. UNIT ACTIVITY TIME-LOCKED TO STIMULUS ONSET IN THE ODOR TASK

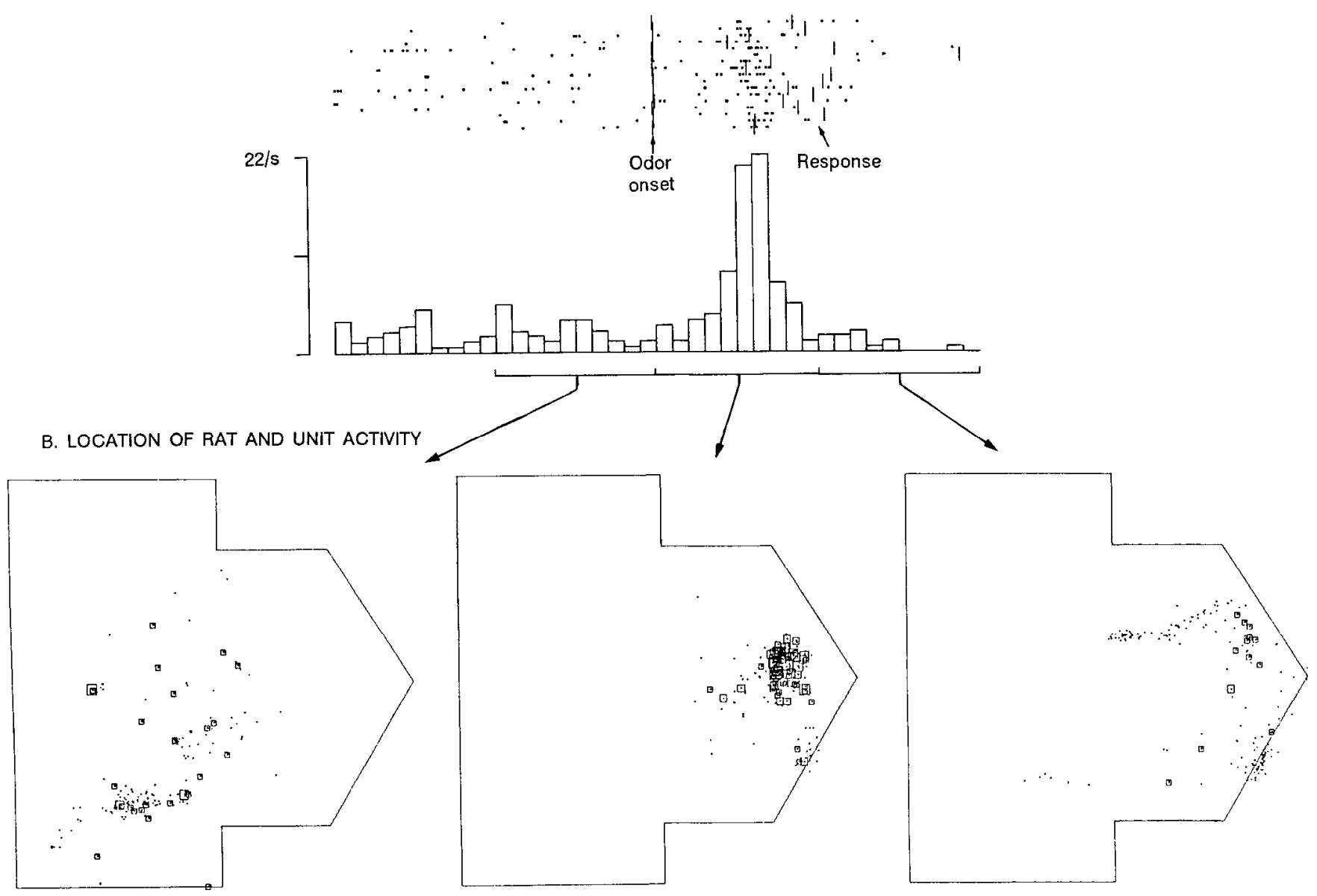

C. ACTIVITY OF THF SAME UNIT IN RELATION TO SPATIAL PARAMETERS IN THE PLACE TASK

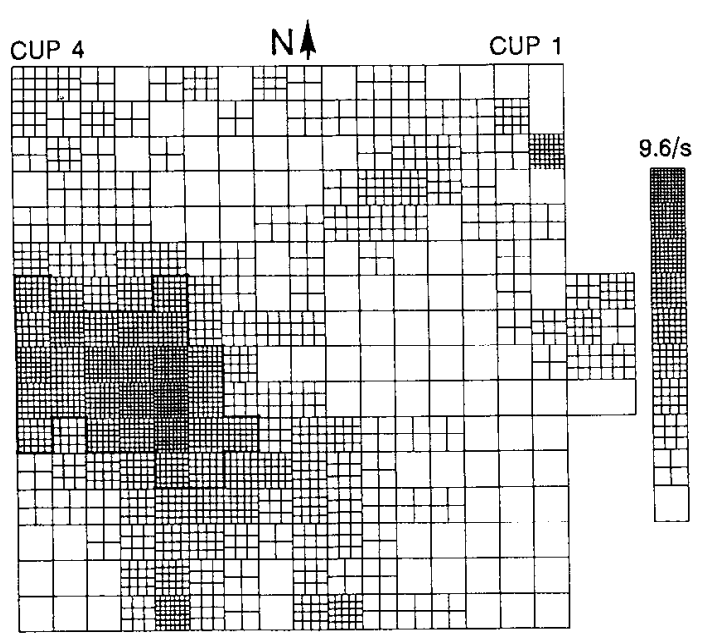

CUP 3
CUP 2

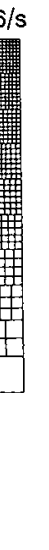

Av. rate $=1.5 / \mathrm{s} 57$ Trials
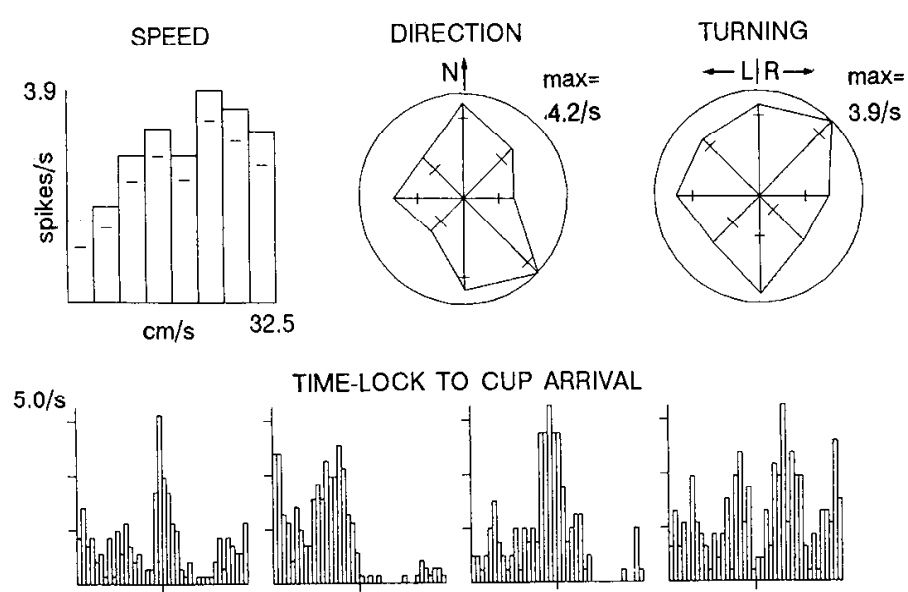

CuP 1

CUP 2

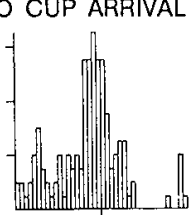

CUP 3

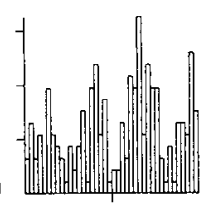

CUP 4

Figure 18. Analyses of a cell that had a cue-sampling correlate in the odor task and spatial and movement correlates in the place task. $A$, In the odor task, raster display (top) and summary histogram (below) show typical spike activity after the odor onset for each trial. $B$, Spatial analyses show that the cell fires as the rat is before the sniff ports only prior to the behavioral response. $C$, In the place task, the cell had a place field near cups 3 and 4 and was tuned to movement speed, direction, and the approach to each cup. Spatial tuning ratio $=3.8$; speed tuning ratio $=2.5$ (minimum $n=160, x^{2}=17.9, d f=7, p<0.02$ ); direction tuning ratio $=2.2$ (minimum $n=64, \chi^{2}=16.5, d f=7, p<0.05$ ), turn tuning ratio, n.s. 
A. UNIT ACTIVITY TIME-LOCKED TO DISCRIMINATIVE RESPONSE IN THE ODOR TASK

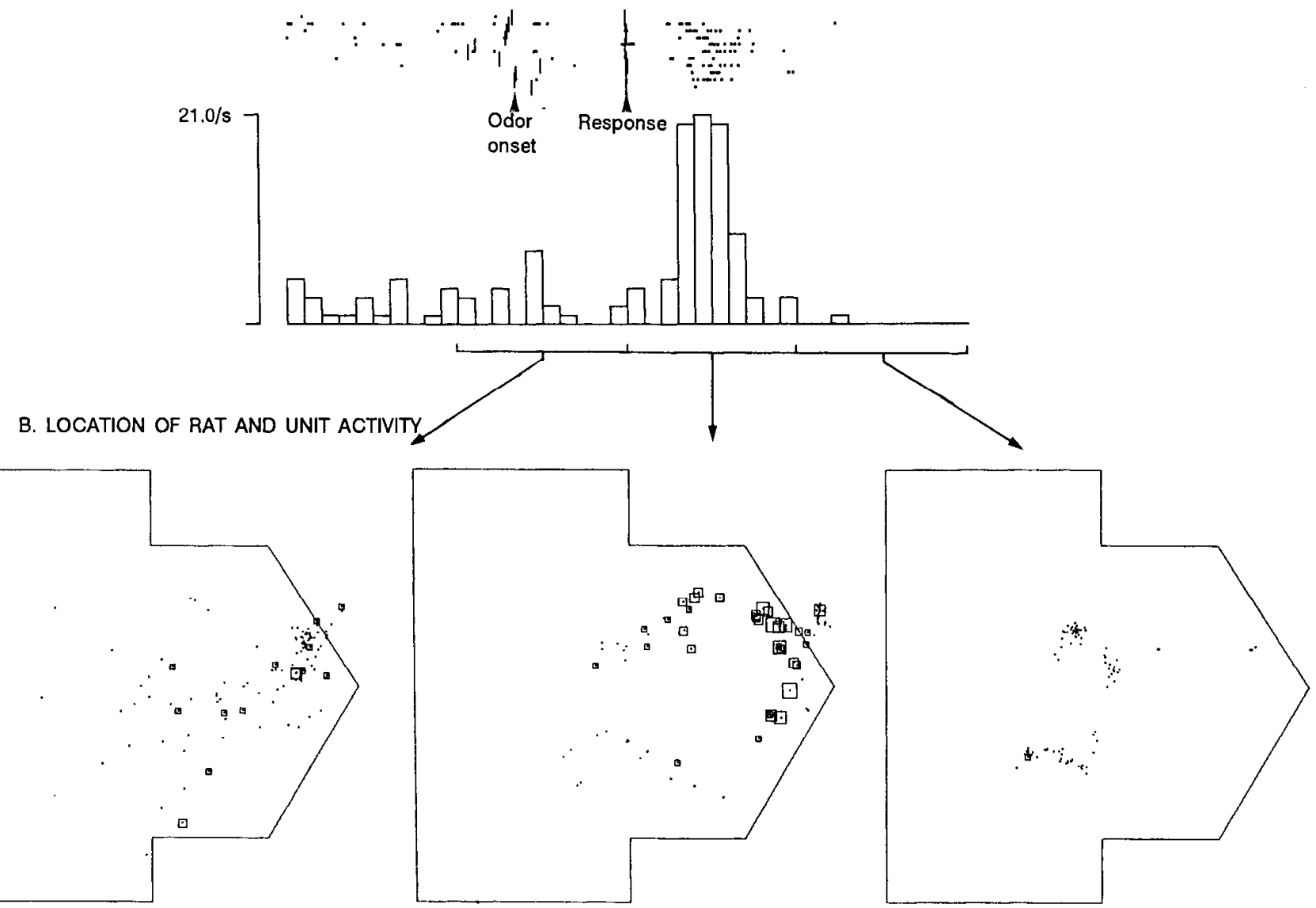

C. ACTIVITY OF THE SAME UNIT IN RELATION TO SPATIAL PARAMETERS IN THE PLACE TASK

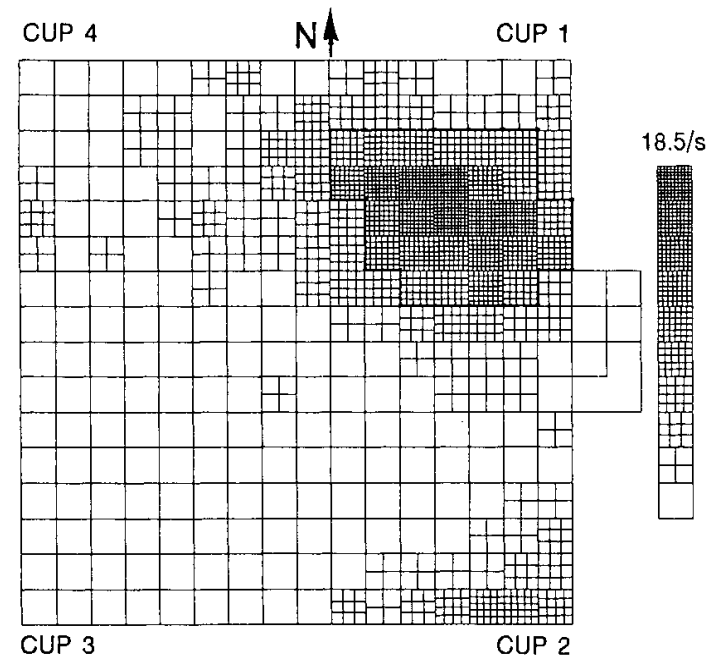

Av. rate $=2.3 / 5 \quad 72$ Trials
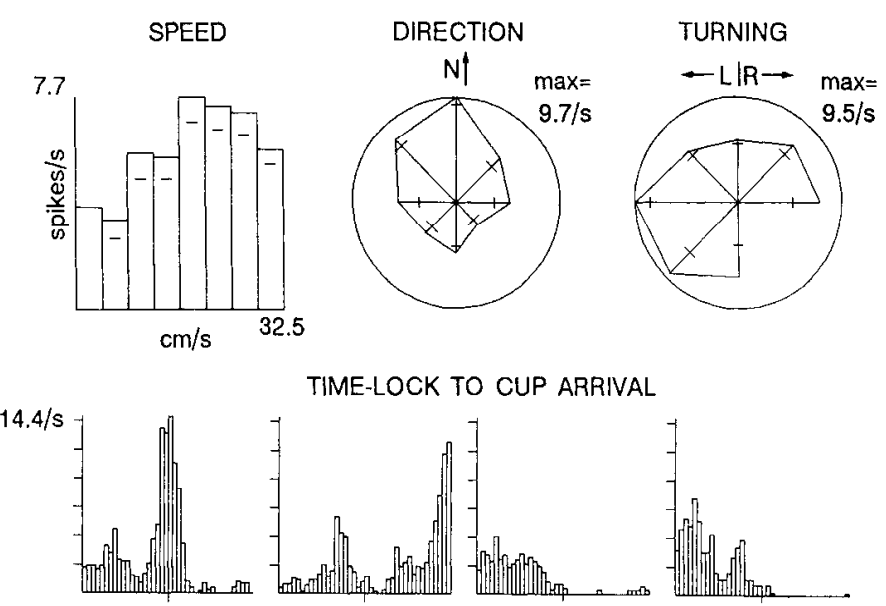

TIME-LOCK TO CUP ARRIVAL

CUP 1

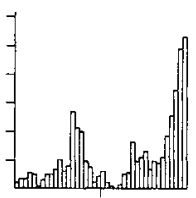

CUP 2

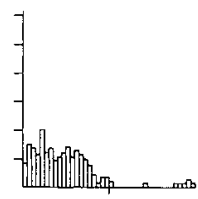

CUP 3

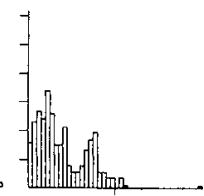

CUP 4

Figure 19. Analyses of a cell that had a goal-approach correlate in the odor task and spatial and movement correlates in the place task. $A$, In the odor task, this cell fired time-locked to the approach to the water cup after the behavioral response and the onset of water delivery. $B$, Spatial analyses for $1 \mathrm{sec}$ periods indicated in $A$ show that the cell did not fire as the rat approached the sniff ports (left panel) but did fire when the rat was at the same locus after it executed the correct discriminative response. $C$, In the place task, the cell had a place field near cup 1 and was tuned to movement speed, direction, turning, and the approach to cups 1, 2, and 4 . Spatial tuning ratio $=6.9 ;$ speed tuning ratio -2.5 (minimum $n=$ $189, \chi^{2}=43.8, d f=7, p<0.001$ ); direction tuning ratio $=3.4$ (minimum $n=40, \chi^{2}=93.8, d f=7, p<0.001$ ), turn tuning ratio $=1.7$ (minimum $\left.n=12, \chi^{2}=19.1, d f=6, p<0.01\right)$. 


\section{A. CUE-SAMPLING CORRELATE $(n-20)$}

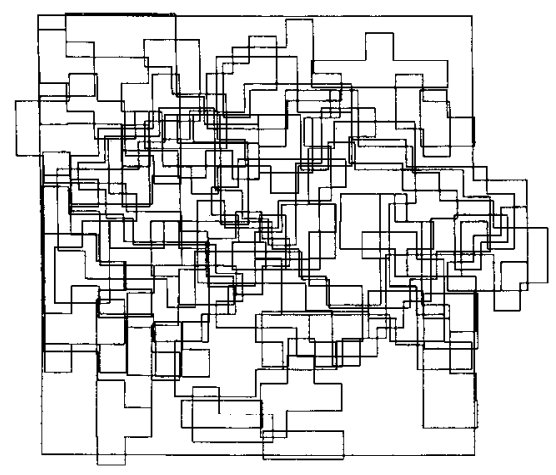

B. GOAL-APPROACH CORRELATE ( $n=22)$

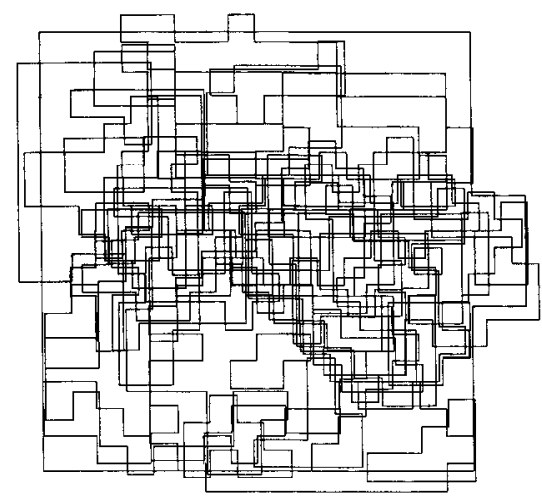

C. NO FIRING INCREASE IN ODOR TASK $(n=24)$

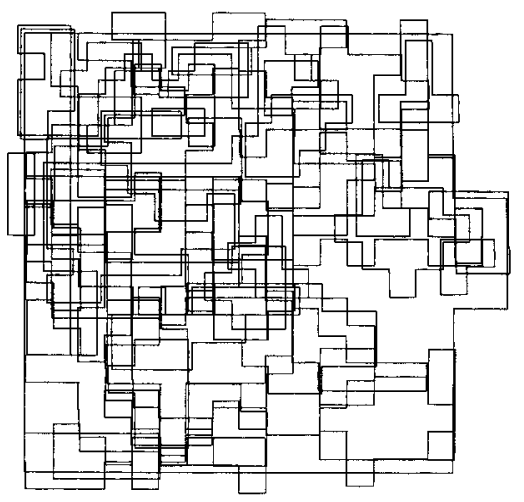

Figure 20. Outlines of the arena indicating the boundaries of the place fields of cells grouped according to their functional correlate in the odor task. In order that each panel has approximately the same number of superimposed place fields, the fields of only half (chosen randomly) of the cclls with no increase in firing are shown.

3 movement variables, specifically movement speed, direction, and turning angle, strongly modulate the infield firing of most cells. Indeed, even when the animal was in the place field, the firing rate of some cells was no higher than the out-of-field rate if the animal was moving at a nonoptimal speed or in a nonoptimal direction or turning angle. In addition, the activity of these cells was often time-locked to task-relevant approach movements.

Previous conclusions about the importance of these variables in accounting for the spatial activity of hippocampal cclls has been mixed. O'Keefe and colleagues (O'Keefe and Nadel, 1978; O'Keefe, 1979) have argued that the activity of hippocampal complex spike cells is determined primarily by the location of the animal in relation to multiple distal cues and is not dependent on the presence of any particular stimulus, the orientation of the animal in the environment, or ongoing behavior. Yet the firing of these cells is not completely explained by location; they do not fire continuously when the animal is in the place field. Instead, the cells fire in sporadic bursts and may not fire at all upon some visits to the place field, suggesting that other variables in addition to, or confounded with, "place" account for the spatial correlate.

McNaughton et al. (1983b; see also Jones-Leonard et al., 1987 ), in describing the activity of hippocampal complex spike cells recorded while rats performed in a radial arm maze, reported that spatial firing is strongly modulated by the direction and, to a lesser extent, by the speed of the animal's movement through the place field. They found that maximal activity was usually selectively associated with either outward movements along particular maze arms during the approach to a rewarded location or with inward movements that initiated a run to another arm. Other, less systematic studies have also reported that at least some place cells fire selectively in relation to the direction or' intention of movement (O'Keefe and Dostrovsky, 1971; Ranck, 1973; O'Keefe, 1976; Oltọn et al., 1978) or to EEG patterns associated with movement (Kubie et al., 1984). The present results confirm the existence of directional tuning and firing correlated with specific behaviors. Furthermore, our results indicate that many cells are also selectively tuned to a particular speed and direction of turning, demonstrating considerable individual variability both in the degree of tuning and in the optimum tuning value for all of these movement parameters. Finally, the optimum and degree of tuning of each of these variables varied considerably for the same cell in different subfields.

The present conclusion on speed tuning differs from that of McNaughton et al. (1983b) in that they reported hippocampal neuronal activity only modestly modulated by movement speed; the firing rate was somewhat higher with more rapid animal movements. One possible explanation for the difference in conclusions may be that McNaughton et al. only described the tuning curve for the population of recorded complex spike cells as a group, possibly obscuring variability in the shape and sensitivity of tuning curves for individual cells. Indeed, in the present investigation, since the modal observation was a monotonic tuning curve, collapsing the data for all cells in an analysis similar to that of McNaughton et al. would have yielded the same resulting poorly tuned, monotonic relationship.

The difference in our conclusion on speed tuning versus that of McNaughton et al. (1983a, b) leads to different interpretations of how speed is coded by hippocampal cells. If all cells increased firing rate as a monotonic function of animal speed, one might properly view speed merely as "modulating" cellular firing rate and conclude that speed was not a psychophysical "value" encoded by the cells. As Ballard (1986) suggested, we can distinguish modulation versus value-coding interpretations by the shapes of tuning curves across the cell population. If speed merely modulates neural activity, we expect that the tuning curves of all cells will indicate a monotonic relationship between speed and firing rate, as McNaughton et al. observed in their population tuning curve. However, if speed values are encoded in neural activity, we expect a set of tuning curves including both monotonic and nonmonotonic (inverted-U) shaped functions with different optima covering the full range of possible speeds (Ballard, 1986). Even though the largest single set of cells as categorized here had monotonic curves, most cells had nonmonotonic tuning curves and a full range of optima was observed. One might expect a flat distribution of optima in a valueencoding system, but 2 factors that frequently bias distributions of continuous functions in neural systems could explain our observation of an overrepresentation of higher optimal speeds (Fig. 7): First, most psychophysical properties are represented 
as exponential functions; if plotted on a log-scale, the distribution of speeds in Figure 7 would flatten. Second, in most sensory and motor systems, some region of the variable range is overrepresented (e.g., the foveal region in striate cortex); possibly there is a requirement for overrepresentation of high speeds in the place task. Even if neither of these explanations ultimately accounts for the skewed distribution of optimal speeds, the demonstration of nonmonotonic speed tuning in many cells even when only some directions are considered (Figs. 6, 8) is consistent with Ballard's characterization of a value-encoded variable and is inconsistent with the view that speed simply modulates firing rate in the present paradigm.

Muller et al. (1987) argued that hippocampal place cells are poorly tuned, if at all modulated, by speed and direction of movement. One explanation for the difference in findings from different laboratories may be related to differences in the degree of goal-directed "structure" of the environment for different behavioral paradigms and in the degree to which movement variables were measured. Thus, in the task used by Muller et al. (1987), an enclosed field in which rats retrieve food pellets placed in random locations, space is unstructured in terms of the goals of movement and cellular activity does not appear to be influenced by the movement variables that were measured. In the radial arm maze, which has a prominent and goal-directed structure in the radial dimension, cells were directionally tuned cither to inward or outward movements (Olton et al., 1978; McNaughton et al., 1983b). In the present task, we were able to evaluate a variety of movement parameters over their entire range of values; we observed that most cells were tuned to each of these parameters differentially. Moreover, it is important to take into account that maximal firing occurred when the rat was executing specific behaviors related to the structure of task demands. Thus, we should consider that tuning to movement variables reflects more than variations in the sensory perspective associated with changes in speed, direction, and turning. It may not be merely coincidental that these variables are all encoded in the same cell. We suggest that optimal values of each variable plus the time-locked activity reflect the execution of specific behavioral acts, rather than the orthogonal coding of a set of movement parameters. That is, the combination of movement tuning optima may constitute a specific behavioral correlate for each cell.

These data suggest that hippocampal complex spike cells do more than encode the animal's position, even in paradigms where spatial stimuli are the predominant task cues. The present findings serve to reconcile the place-cell phenomenon with observations that hippocampal complex spike cells fire in relation to specific approach or investigatory behaviors (O'Keefe and Dostrovsky, 1971; Ranck, 1973; O'Keefe, 1976; Eichenbaum et al., 1987). More so than in previous work, the present observations indicate that hippocampal complex spike cell firing relfects how the animal acts in space during behaviors relevant to task demands. That is, hippocampal cell activity is best described in terms of multiple variables that are associated with the active behavior of the animal in space, not merely a passive reflection of location in space. The importance of encoding of spatially directed movements for memory processing has yet to be fully explored, but recent evidence offered by Gaffan and colleagues suggests that the amnesia consequent to hippocampal system damage may be explained, at least in part, as a defect in memory for associations between specific stimuli and voluntary movements (Gaffan, 1985; Rupniak and Gaffan, 1987).
Behavioral and spatial correlates of hippocampal unit activity during performance of a sensory-discrimination task

Hippocampal neurons are activated selectively during specific events relevant to performance on simultaneous-cue odor discrimination. We identified 2 major functional categories that are distinguished by their behavioral correlates. One group of cells fired selectively upon the rats' approach movements towards the cul-de-sac where discriminations were performed or upon its approach to the site of water-reward delivery. We classified these cells as a single functional category called "goalapproach cells," hecause each of these behaviors involves an approach towards critical task targets, and since a significant number of cells fired during both of these behaviors. In contrast, the other major group of cells fired selectively while the rat was relatively motionless, sampling the odor cues and generating the discriminative response. Many of these cells fired differentially with respect to the identity of the odor cues, with respect to their presentation position, or with respect to the configuration of the odors and their presentation positions. Because these correlates reflect variables important to the analysis of relevant discriminative cues and response choices, we classified the cells as "cue-sampling cells."

Other investigators have proposed similar complementary functional categories of hippocampal complex spike cells. Based on a different bchavioral paradigm, O'Keefe (1976) described some hippocampal complex spike cells as place cells, involved in spatial guidance, and others as misplace cells, involved in the identification of unexpected changes in the environment. Ranck (1973) described approach-consummate cells as involved in appetitive behaviors and approach-consummate-mismatch cells as involved in recognizing the absence of expected reward. In our previous study, we suggested that the 2 major cell types observed in each of the above studies play complementary roles, specifically that goal-approach cells reflect the orienting of attention to important cues and that cue-sampling cells reflect the processing of relationships among these cues (Eichenbaum et al., 1987). The present data add support to that view.

The present findings, combined with those from our previous study (Eichenbaum et al., 1987), also serve to clarify previous characterizations of behavioral correlates of hippocampal neuronal activity. The findings for each of our main functional categories will be summarized separately.

Cue-sampling cells. The current data confirm those of our previous study of cue-sampling cells in a successive-cue odor discrimination, even though that paradigm differed in the manner of stimulus presentation, in the response requirement, and in the degree to which performance depended on an intact hippocampal system (Eichenbaum et al., 1986, 1987, 1988). In both the current and previous paradigms, these cells fired in synchrony with the ongoing sniff and theta rhythms as the rat investigated the odor cues. The present findings also extended our understanding of the cue-sampling correlate. In the previous study, a nose-poke initiated odor onset and continuing the nosepoke served as the behavioral response. This confounded the investigatory behavior associated with odor analysis with the execution of the discriminative response. In the present study, the onset of odor sampling and the discriminative response were distinct. Our present results show that the firing of cue-sampling cells is selective to the odor-analysis period, leading up to execution of the behavioral response. Also, in the previous study, odors were presented at only one location, thus confounding 
behaviors towards the relevant cue with the locus of cue presentation. The present results show that some of these cells fired when the rat was sampling odors at multiple separate loci (Fig. 11). In addition, some cue-sampling cells fire in relation to the odors presented (Figs. 13, 14), their presentation positions (Figs. 12-14), and the interaction of these 2 variables (Figs. 13, 14). Ranck (1973) and O'Keefe (1976) have previously described cells that fire selectively during investigatory sniffing in behavioral paradigms quite different from ours. But in all of these studies, hippocampal cells were not activated merely by sniffing. Rather, the units fired selectively as rats explored actual or expected stimuli of known significance.

The present data confirm other results indicating that hippocampal neuronal activity reflects the configurations of discriminative cues and response-choices in different learning tasks. Wible et al. (1986) trained rats to perform a color-cued, delayed nonmatch to sample task in a Y-maze. They found that some hippocampal neurons were differentially active as the rat was in a choice arm associated with a particular color, a particular position, or the interaction of these variables. Similarly, Rolls et al. (1985) trained monkeys to perform a pattern-cued matching task and found that some hippocampal neurons fired selectively as the monkey responded to a particular pattern in a particular position on the choice panel.

Goal-approach cells. In both our earlier paradigm and in the present study, goal-approach cells fired selectively as the rat moved towards the relevant targets associated with the discriminative stimuli or rewards. Several other laboratories have described behavioral correlates of hippocampal complex spike cells. Ranck (1973) observed cells that fired selectively during appetitive and approach movements. Berger et al. (1983) found that many hippocampal cells fire selectively during a conditioned eyeblink movement. Watanabe and Niki (1985) and Wilson et al. (1987) also described hippocampal cells that fire in relation to particular combinations of stimuli and behavioral responses in monkeys. While some of these observations involve movements to targets defined by their spatial positions, others (e.g., Berger et al.) have no spatial component. Each of these findings is consistent with the view that many hippocampal neurons fire selectively during specific appetitive movements.

\section{On the role of "place" in the behavioral correlates of cellular} activity in the odor task

It is important to consider whether these behavioral correlates can be explained simply in terms of spatial preferences for unit firing. Considerable evidence provided here indicates that spatial location is, at best, only a partial predictor of firing both in cue-sampling cells and in goal-approach cells. While cue-sampling cells fired only when the rats were at the locus of the sniff ports, firing was limited to the period of investigatory behavior; these cells ceased firing abruptly upon the discriminative response, even though the rat remained in the identical place, facing in the same direction (Fig. 10). The firing of port-approach cells was not spatially localized, but was well time-locked to the movements associated with trial initiation (Fig. 16). The activation of cup-approach cells, like that of cue-sampling cells, was necessarily associated with the places where these behaviors were performed, but cup-approach cells fired only during the movement out of the ports and not while the rat passed through the same locus prior to the discriminative response (Fig. 17). Furthermore, firing occurred only as the rat withdrew from the port to approach the reward cup and not as the rat moved through the same location in the same direction to investigate the other sniff port. These characteristics of cellular activity cannot be explained merely by spatial location, even in combination with direction; the ongoing behavior must be considered.

The role of space in the determination of behavioral correlates observed here seems substantially different than that proposed by O'Keefe and Nadel (1978). According to their theory of the hippocampus as a cognitive map, the hippocampus represents space in at least roughly Cartesian coordinates. However, the left/right distinction observed as a critical variable here implies quite a different spatial dimension. Rather than composing Cartesian space, the spatial variable encoded here is the pairwise "position" or "configuration" of specific cues.

\section{What hippocampal complex spike cells encode: towards a reconciliation of "place" and "behavioral" correlates of hippocampal neuronal activity}

A major finding of the present study is that hippocampal complex spike cells can have seemingly unrelated "place" and "behavioral" correlates in different tasks that each demand hippocampal function, even when these tasks are performed in the same environment. For example, the same cells whose activity increased selectively during relatively immobile stimulus-sampling behavior in an odor-discrimination task also had distinct place fields distant from the odor-sampling area and were tuned to specific movements in a spatial-navigation task (e.g., Fig. 18). While individual cells were often better tuncd to fcatures of onc task or the other, the functional correlates in both tasks were usually significant and often both functional correlates were striking.

One explanation that has been offered to account for the disparate characterizations of hippocampal neuronal activity in terms of "place" correlates in some paradigms versus "behavioral" correlates in other paradigms was that anatomically and physiologically distinct classes of hippocampal cells subserve these different representations. Christian and Deadwyler (1986) showed that CA1 complex spike cells recorded in rats exploring an open platform have place fields, but these cells do not, as a group, increase activity reliably in response to a tone signaling reward in an auditory-discrimination task. Conversely, theta cells showed large tone-evoked increases in activity during learning, but did not have place fields on the open platform. These findings are difficult to reconcile with data from the same laboratory demonstrating that the responses of CA1 cells to conditioned tones varies with prior experience (Foster et al., 1986), and with the results of others demonstrating tone-evoked conditioned responses in CA1 complex spike cells of rats performing a similar auditory conditioning task (Segal et al., 1972) and of rabbits performing a classically conditioned eyeblink response (Berger et al., 1983).

It seems more likely that the same circuits in the hippocampal formation subserve both representations. Consistent with this view, in a preliminary study, Best and Thompson (1984) showed that the same hippocampal complex spike cells that had place fields as rats exploring a radial maze showed tone-evoked conditioned responses in a conditioned emotional response paradigm. Moreover, the present data demonstrate that many of the same hippocampal complex spike cells that have place correlates in a spatial navigation task also have highly selective behavioral correlates in an odor-discrimination task. 
One interpretation of these findings that incorporates both spatial and behavioral correlates is the view that the hippocanpus flexibly "remodels" itself to represent significant features of both tasks. By this hypothesis, the hippocampus acts as a random associative network in which individual neuronal elements become tuned to conjunctions of stimuli, at least some of which may be derived from the animal's own behavior (Marr, 1971; McNaughton and Morris, 1987; also see Eichenbaum and Cohen, 1988). If this were the case, one would not expect to observe any relationship between functional correlates across tasks. Indeed, we could find no obvious relationship between the specific qualities of functional correlates of cells recorded in both the odor and place tasks. However, 2 general consistencies were observed. (1) Cells that had cue-sampling correlates in the odor task had significantly smaller place fields than goal-approach cells in the place task. (2) Cells that had cue-sampling correlates in the odor task were more likely to have higher peak firing rates in the odor task than in the place task; cells with goalapproach correlates were more likely to have a higher peak firing rate in the place task. These qualities suggest that hippocampal neurons have some degree of fixed tuning properties, suggesting that the hippocampus is not a totally random neural network with completely indeterminate coding in individual elements.

An alternative interpretation is that the hippocampus has a fixed representation, or only a limited "remodeling" capacity, and that its network serves to process specific but abstract features that are common across tasks that invoke hippocampal function. By this view, individual neural elements have builtin tuning preferences, presumably due to the known gradients of hippocampal inputs and association systems (Swanson and Cowan, 1977), but the features to which elements are tuned cannot be associated simply with specific stimuli or movements that are unique to one type of task. Rather, the cells are tuned to higher-order features common across stimulus and response modalities, and most cells are activated in many behavioral paradigms. Individual cells might be more activated in a particular task fortuitously because that task contains particular parameter values for which a cell is better tuned. Our findings showing highly specific responses of cells with different odortask correlates is consistent with this view. Cells with cue-sampling correlates in the odor task may be more sensitive to behavioral events associated with motionlessness, sniffing, or odor stimuli, events that are relatively rare in the place task. Thus, these cells seem better tuned to events in the odor task. Conversely, cells with goal-approach correlates in the odor task may be more sensitive to behavioral events associated with running, drinking, or distant visual cues, events that are even more prevalent in the place task than in the odor task. Thus, these cells seem to be better tuned to events in the place task.

\section{A view of hippocampal representation in memory processing}

Further clarification of the significance of these findings for memory processing comes from comparing the present data with results from studies demonstrating learning impairments after hippocampal system damage. An emerging consensus in the interpretation of these studies has indicated that the hippocampus is critical to learning and memory over a large range of information modalities that share a common demand for representing relationships among multiple independent percepts, but not for acquiring independent stimulus-reinforcement associations. For example, with regard to spatial learning, an intact hippocampal system is necessary for learning places defined by multiple distant cues, but not for associating a particular distinctive cue contiguous with a reward site (O'Keefe and Conway, 1980). With regard to discrimination learning, the hippocampal system is required for learning odor discriminations when the stimuli are presented simultaneously so as to encourage comparison of relationships among cues, but the learning of separate odor-reward associations is normal even after the disruption of hippocampal pathways (Eichenbaum et al., 1986, 1988). A survey of the literature indicates a critical role for hippocampal system function in 2 related domains of learning. First, the hippocampus contributes to temporal processing of memory for comparisons of a current cue to specific previous experiences, for example, in delayed matching and nonmatching tasks. This demand for retaining information and comparing experiences across a delay has been captured in various theoretical formulations as "working memory" (Olton et al., 1979), "representational memory" (Thomas and Gash, 1986), "temporal contiguity" (Solomon, 1980; Rawlins, 1985), and "episodic memory" (Kesner, 1980; Schacter and Tulving, 1983; Tulving, 1983). Second, the hippocampus contributes to configurational processing involving memory for interdependencies among perceptually independent cues, as important, for example, in "place" learning or memory for "context." This demand for representing configurational information has been captured in theoretical formulations as "contextual encoding" (Hirsh, 1974; Winocur, 1980) and "memory" (Mishkin and Petri, 1983; Mishkin et al., 1983), as well as "cognitive mapping" (O'Keefe and Nadel, 1978). In our view, both kinds of processing involve the creation and maintenance of relational representations, supporting comparisons either between perceptually independent cues presented at the same time (configurational) or between individual cues and their subsequent reoccurrence sequentially (temporal).

Evidence from neurophysiological studies indicates that the activity of hippocampal neurons is influenced by the temporal and configurational features that are emphasized in our working hypothesis about hippocampal-system function derived from the results of lesion studies. Hippocampal neuronal activity reflects previous specific experience with stimuli presented sequentially (Watanabe and Niki, 1985; Foster et al., 1986; Eichenbaum et al., 1987; cf. Olton, 1988) and reflects the configurations or conjunctions of multiple stimuli presented simultaneously (O'Keefe, 1979; Rolls et al., 1985; Wible et al., 1986). In our own work, cue-sampling cells seem to code the relevant relations among cues across variates of the same task. In successive-cue discrimination, the activity of these cells reflects the sequence of $\mathrm{S}^{+}$and $\mathrm{S}^{-}$stimuli, suggesting that the hippocampus is involved in representing the relationships between the stimuli and outcomes across trials. This finding is similar to Deadwyler and colleagues' description of "sequential dependencies" in hippocampal unit activity across trials in a tone-cued discrimination (Foster et al., 1986). In the current simultaneous-cue discrimination, the activity of cue-sampling cells reflects the configuration of odors and their presentation position, suggesting that the hippocampus is involved in representing the configuration of multiple cues and choices. As described above, this result is similar to reports of cells that respond to configurations of visual cues and their presentation position in monkeys and rats.

Furthermore, the multimodal qualities of stimuli controlling "place" firing in hippocampal units are also consistent with our hypothesis that the hippocampus processes configurations and relationships among relevant cues and events. Place fields of 
hippocampal cells are contingent on particular visual and auditory cues and their arrangement (O'Keefe and Conway, 1978). Also, place fields maintain a consistent spatial relationship to salient cues, even when the environment changes in size (Muller and Kubie, 1987), However, when the shape of the environment changes, altering the relations among salient cues, place fields change unpredictably.

Finally, considering the present findings, it may be said that the current focus on the representation of environmental stimuli by the hippocampus is not sufficient. Place-related unit activity during a spatial navigation task is time-locked to appetitive movements. Furthermore, the selective activity of cue-sampling and goal-approach cells in the odor task occurs in the context of appetitive movements associated with stimulus-sampling or approach behaviors. The strong dependence on active behavioral output suggests that we must consider both action as well as stimulus variables in our models of information processing in the hippocampal circuit. Hence, both the configuration of the cues within the environment and the animal's actions on the environment are reflected in hippocampal neuronal activity. Combined, these correlates implicate hippocampal circuits in the processing of configurations or conjunctions of the multiple cues and behaviors that guide performance in both spatial and nonspatial tasks.

In summary, the data from both lesion and recording studies over a wide range of tasks are beginning to converge. The evidence strongly argues against the notion that hippocampal function is modality specific. That is, learning impairments resulting from hippocampal system damage are not restricted to a particular sensory or multisensory (e.g., spatial) mode, and hippocampal neurons are not active solely in relation to stimuli of any particular sensory or multisensory mode. Rather, what ties the pattern of memory impairments in animals with hippocampal system damage to the pattern of functional correlates found in hippocampal neuronal activity is the importance of configurations. conjunctions, or relationships of multiple cues that guide active performance (Eichenbaum et al., 1988). The scope of abstract relationships that are processed by the hippocampus and the qualities of representation by which the hippocampus processes relationships and contingencies among cues are matters of considerable current speculation (Squire et al., 1984; Lynch, 1986; Teyler and DiScenna, 1986; McNaughton and Morris, 1987; Eichenbaum and Cohen, 1988).

\section{References}

Ballard, D. H. (1986) Cortical connections and parallel processing: Structure and function. Behav. Brain Sci. 9: 67-120.

Berger, T. W., P. C. Rinaldi, D. J. Weisz, and R. F. Thompson (1983) Single-unit analysis of different hippocampal cell types during classical conditioning of the nictitating membrane response. J. Neurophysiol. 50: $1197-1219$.

Best, P. J. (1988) Workshop: Hippocampal cellular activity and spatial-cognitive processing. Soc. Neurosci. Abstr. 14: 595.

Best, P. J.. and L. T. Thompson (1984) Hippocampal cells which have place field activity also show changes in activity during classical conditioning. Soc. Neurosci. Abstr. 10: 125.

Christian, E. P., and S. A. Deadwyler (1986) Behavioral functions and hippocampal cell types: Evidence for two nonoverlapping populations in the rat. J. Neurophysiol. 55: 331-348.

Eichenbaum, H., and N. J. Cohen (1988) Representation in the hippocampus: What do hippocampal neurons code? Trends Neurosci. 11: 244-248.

Eichenbaum, H., D. Pettijohn, A. M. Deluca, and S. L. Chorover (1977) Compact miniature microelectrode-telemetry system. Physiol. Behav. 18: $1175-1178$.
Eichenbaum, H., A. Fagan, and N. J. Cohen (1986) Normal olfactory discrimination learning set and facilitation of reversal learning after medial-temporal damage in rats: Implications for an account of preserved learning abilities in amnesia. J. Neurosci. 6: 1876-1884.

Eichenbaum, H., M. Kuperstein, A. Fagan, and J. Nagode (1987) Cuesampling and goal-approach correlates of hippocampal unit activity in rats performing an odor discrimination task. J. Neurosci. 7: 716732.

Eichenbaum, H., A. Fagan, P. Mathews, and N. J. Cohen (1988) Hippocampal system dysfunction and odor discrimination learning in rats: Impairment or facilitation depending on representational demands. Behav. Neurosci. 102: 331-339.

Foster, T. C., E. P. Christian, R. E. Hampson, K. A. Campbell, and S. A. Deadwyler (1986) Sequential dependencies regulate sensory evoked responses of single units in the rat hippocampus. Brain Res. 408: 86-96.

Fox, S. E., and J. B. Ranck (1975) Localization and anatomical identification of theta and complex spike cells in dorsal hippocampus in rats. Exp. Neurol. 49: 299-313.

Gaffan, D. (1985) Hippocampus: Memory, habit and voluntary movement. Phil. Trans. R. Soc. Lond. B 308: 87-99.

Hill, A. J. (1978) First occurrence of spatial firing in a new environment. Exp. Neurol. 62: 282-297.

Hill, A. J., and P. J. Best (1981) Effects of deafness and blindness on the spatial correlates of hippocampal unit activity in the rat. Exp. Neurol. 74: 204-217.

Hirsh. R. (1974) The hippocampus and contextual retrieval of information from memory: A theory. Behav. Biol. 12: 421-444.

Jones-Leonard, B., B. L. McNaughton, and C. A. Barnes (1987) A multiple regression analysis of behavioral correlates of rat hippocampal neuron discharge. Soc. Neurosci. Abstr. 13: 1125.

Kesner, R. P. (1980) An attribute analysis of memory: The role of the hippocampus. Physiol. Psychol. 8: 189-197.

Kubie, J. L. (1984) A driveable bundle of microwires for collecting single-unit data from freely moving rats. Physiol. Bchav. 32: 115118.

Kubie, J. L., and J. B. Ranck (1983) Sensory-behavioral correlates in individual hippocampus neurons in three situations: Space and context. In Neurobiology of the Hippocampus, W. Seifert, ed., pp. 433448, Academic, New York.

Kubie, J. L., S. E. Fox, and R. U. Muller (1984) Variations in place cell firing with the state of the hippocampal EEG. Soc. Neurosci. Abstr. 10:599.

Kuperstein, M., H. Eichenbaum, and T. VanDeMark (1986) Neural group properties in the rat hippocampus during the theta rhythm. Exp. Brain Res. 61: 438-442.

Lynch, G. (1986) Synapses, Circuits, and the Beginnings of Memory, MIT Press, Cambridge, MA.

Macrides, F. (1975) Temporal relationships between hippocampal slow waves and exploratory sniffing in hamsters. Behav. Biol. 14: 295308.

Macrides, F., H. Eichenbaum, and W. B. Forbes (1982) Tcmporal relationship between sniffing and the limbic theta rhythm during odor discrimination reversal learning. J. Neurosci. 2: 1705-1717.

Marr. D. (1971) Simple memory: A theory for archicortex. Phil. Trans. R. Soc. Ser. B 262: 23-81.

McNaughton, B. L., and R. G. M. Morris (1987) Hippocampal synaptic enhancement and information storage within a distributed memory system. Trends Neurosci. 10: 408-415.

McNaughton, B. L., J. O'Keefe, and C. A. Barnes (1983a) The stercotrode: A new technique for simultaneous isolation of several single units in the central nervous system from multiple unit records. J. Neurosci. Methods 8: 391-397.

MeNaughton, B. L., C. A. Barnes, and J. O'Keefe (1983b) The contributions of position, direction, and velocity to single cell unit activity in the hippocampus of freely moving rats. Exp. Brain Res. 52: 4149.

Miller, V. M., and P. J. Best (1980) Spatial correlates of hippocampal unit activity are altered by lesions of the fornix and entorhinal cortex. Brain Res. 194: 311-323.

Mishkin, M., and H. L. Petri (1983) Memories and habits: Some implications for the analysis of learning and retention. In The Neuropsychology of Memory, N. Butters and L. R. Squire, eds., Guilford, New York.

Mishkin, M., B. Malamut, and J. Bachevalier (1983) Memories and 
habits: Two neural systems. In The Neurobiology of Learning and Memory, J. L. McGaugh, G. Lynch and N. Weinberger, eds., Guilford, New York.

Muller, R. U., and J. L. Kubie (1987) The effects of changes in the environment on the spatial firing of hippocampal complex-spike cells. J. Neurosci. 7: 1951-1968.

Muller, R. U., J. L. Kubie, and J. B. Ranck (1987) Spatial firing patterns of hippocampal complex-spike cells in a fixed environment. J. Neurosci. 7: 1935-1950.

O'Keefe, J. A. (1976) Place units in the hippocampus of the freely moving rat. Exp. Neurol. 51: 78-109.

O'Keefe, J. A. (1979) A review of hippocampal place cells. Prog. Neurobiol. 13: 419-439.

O'Keefe, J., and D. H. Conway (1978) Hippocampal place units in the freely moving rat: Why they fire when they fire. Exp. Brain Res. 31: $573-590$.

O'Keefe, J., and D. H. Conway (1980) On the trail of the hippocampal engram. Physiol. Psychol. 8: 229-238.

O'Keefe, J., and J. Dostrovsky (1971) The hippocampus as a spatial map. Preliminary evidence from unit activity in the freely moving rat. Brain Res. 34: 171-175.

O'Keefe, J., and L. Nadel (1978) The Hippocampus as a Cognitive Map, Oxford U. P., Oxford, UK.

O'Keefe, J. A., and A. Speakman (1987) Single unit activity in the hippocampus during a spatial memory task. Exp. Brain Res. 68: 127.

Olton, D. S. (1988) Mnemonic functions of the hippocampus: Single unit analyses in rats. In The Hippocampus: New Vistas, V. ChanPalay, ed. (in press).

Olton, D. S., and R. J. Samuelson (1976) Remembrance of places past: Spatial memory in rats. J. Exp. Psychol. 2: 97-116.

Olton, D., M. Branch, and P. J. Best (1978) Spatial correlates of hippocampal unit activity. Exp. Neurol. 58: 387-409.

Olton, D. S., J. T. Becker, and G. E. Handlemann (1979) Hippocampus, space, and memory. Brain Behav. Sci. 2: 313-365.

Ranck, J. B. (1973) Studies on single neurons in the hippocampal formation and septum in unrestrained rats. Part I. Behavioral correlates and firing repertoires. Exp. Neurol. 40: 461-531.

Rawlins, J. N. P. (1985) Associations across time: The hippocampus as a temporary memory store. Brain Behav. Sci. 8: 479-496.

Rolls, E. T., Y. Miyashita, P. Cahusac, and R. P. Kesner (1985) The responses of single neurons in the primate hippocampus related to performance in memory tasks. Soc. Neurosci. Abstr. 11: 525.

Rupniak, N. M. J., and D. Gaffan (1987) Monkey hippocampus and learning about spatially directed movements. J. Neurosci. 7: 23312337.

Schacter, D., and E. Tulving (1983) Memory, amnesia, and the episodic/semantic distinction. In The Expression of Knowledge, R. L. Isaacson and N. E. Spear, eds., Plenum, New York.

Segal, M., J. Disterhoft, and J. Olds (1972) Hippocampal unit activity during aversive and appetitive conditioning. Science 175: 792-794.

Siegel, S. (1958) Non-Parametric Statistics for the Behavioral Sciences, McGraw-Hill, New York.

Solomon, P. R. (1980) A time and a place for everything? Temporal processing views of hippocampal function with special reference to attention. Physiol. Psychol. 8: 254-261.

Squire, L. R., N. J. Cohen, and L. Nadel (1984) The medial temporal region and memory consolidation: A new hypothesis. In Memory Consolidation: Psychobiology of Cognition, IH. Weingartner and E. Parker, eds., pp. 185-210, Erlbaum, Hillsdale, NJ.

Swanson, L. W., and W. M. Cowan (1977) An autoradiographical study of the organization of the efferent connections of the hippocampal formation in the rat. J. Comp. Neurol. 172: 49-84.

Teyler, T. J., and P. DiScenna (1986) The hippocampal memory indexing theory. Behav. Neurosci. 100: 147-154.

Thomas, G. J., and D. M. Gash (1986) Differential effects of posterior septal lesions on dispositional and representational memory. Behav. Neurosci. 100: 712-719.

Tulving, E. (1983) Elements of Episodic Memory, Oxford U. P., Oxford, UK

Watanabe, T., and H. Niki (1985) Hippocampal unit activity and delayed response in the monkey. Brain Res. 325: 241-254.

Wible, C. G., R. L. Findling, M. Shapiro, E. J. Lang, S. Crane, and D. S. Olton (1986) Mnemonic correlates of unit activity in the hippocampus. Brain Res. 399: 97-110.

Wilson, F. A. W., M. W. Brown, and I. P. Riches (1987) Neuronal activity in the inferomedial temporal cortex compared with that in the hippocampal formation: Implications for amnesia of medial temporal lobe origin. In Cellular Mechanisms of Conditioning and Behavioral Plasticity, C. D. Woody, ed., Plenum, New York.

Winocur, G. (1980) The hippocampus and cue utilization. Physiol. Psychol. 8: 280-288. 